\title{
Thermo-mechanical behavior simulation coupled with the hydrostatic-pressure-dependent grain-scale fission gas swelling calculation for a monolithic UMo fuel plate under heterogeneous neutron irradiation
}

https://doi.org/10.1515/eng-2018-0029

Received September 27, 2017; accepted June 28, 2018

\begin{abstract}
Monolithic UMo fuels have a higher uranium density than previously developed fuels. They have become the most promising fuels to be used in high-flux research and test reactors after the US Office of Material Management and Minimization Reactor Conversion Program (formerly Reduced Enrichment Research and Test Reactor (RERTR) program). In this study, a computational method is established to couple the macro-scale irradiation-induced thermo-mechanical behavior simulation with the hydrostatic-pressure-dependent fission gas swelling calculation in the UMo grain. The stress update algorithms and consistent stiffness moduli are respectively presented for UMo fuel, in which both the hydrostaticpressure-dependent irradiation swelling and deviatoricstress-directed irradiation creep are taken into account. Accordingly, the user subroutines to define the thermomechanical non-homogeneous constitutive relations for the UMo fuel meat and Al cladding are developed and validated. The in-pile behavior in a monolithic UMo fuel plate under a location-dependent irradiation condition is calculated and discussed.
\end{abstract}

Keywords: Heterogeneous irradiation; incremental constitutive relations; stress update algorithms; consistent stiffness moduli; hydrostatic-pressure-dependent fission gas swelling

\footnotetext{
Xiangzhe Kong, Xu Tian, Feng Yan: Institute of Mechanics and Computational Engineering, Department of Aeronautics and Astronautics, Fudan University, Shanghai 200433, China

*Corresponding Author: Shurong Ding: Institute of Mechanics and Computational Engineering, Department of Aeronautics and Astronautics, Fudan University, Shanghai 200433, China, E-mail: dsr1971@163.com
}

\section{Introduction}

In the 1970s, the USA proposed a program called RERTR [1] (The Reduced Enrichment for Research and Test Reactors) with the aim of replacing highly enriched uranium (HEU) with low enriched uranium (LEU) for civilian use. To ensure the required neutron flux, the alternative fuels should possess a high effective density of uranium. A UMo monolithic fuel with $7-10 \mathrm{wt} \%$ Mo [2-4] is the most promising candidate to be used in some high-flux research and test reactors, for its highest effective density of uranium and good irradiation stability.

The UMo monolithic fuel plate consists of two parts, with the Al-cladding metallurgically bonded with a UMo alloy meat. In order to perform optimal design for the reactor core and monolithic fuel plates, the in-pile irradiationinduced thermo-mechanical behavior in the fuel plates needs to be investigated, similar to the need for fuel rods [5]. A number of irradiation experiments [6-10] have been implemented, and the experimental results indicated that the irradiation swelling curves for UMo fuels had distinct inflection points, after which the irradiation swelling was accelerated [6]. Post irradiation examination demonstrated that grain recrystallization occurred [6] to trigger this phenomenon. Plenty of fine grains will take the place of original coarser fuel grains; thus, the fission gas atoms can diffuse quickly to the new grain boundary to form large intergranular bubbles. The irradiation swelling mainly results from the fission solid swelling and the aforementioned intergranular bubble swelling, which leads to remarkable mechanical interactions between the fuel meat and cladding. Simultaneously, it should be noted that intergranular bubble swelling depends on external hydro-

Shenyang Hu, Douglas E. Burkes: Pacific Northwest National Laboratory, Richland, WA 99352, USA 
static pressure. It can be determined that in-pile thermomechanical behavior evolution is coupled with the grainscale fission gas behavior.

In addition to experimental research, some theoretical contributions have been reported. Empirical formulas for UMo fuel swelling [6] were given according to experimental results, in which the swelling relations as a function of fission density were divided by the critical fission density, at which recrystallization occurred. Rest et al. [11] developed a fission gas swelling model that took recrystallization into account, and the obtained fission gas swelling was based on the calculation of the grain-scale fission gas diffusion behavior. Cui et al. [12] further improved the fission gas swelling model with consideration of hydrostatic pressure and re-solution of intergranular gas atoms, and it was used to simulate the in-pile behavior in a monolithic fuel plate under uniform neutron irradiation [12]. The simulation researches $[7,13,14]$ on the inpile thermo-mechanical behavior in monolithic and dispersion UMo fuel plates tend to increase gradually. As we know, fuel plates in the reactor core are under a heterogeneous irradiation condition [7]. Some simulations [15, 16] have involved this effect, however, the empirical formulas for UMo fuel swelling were used. The irradiation-induced thermo-mechanical simulation should be further correlated with the grain-scale fission gas behavior.

In this study, a grain-scale fission gas swelling model involving recrystallization, hydrostatic pressure dependence and intergranular gas atom re-solution is introduced into the mechanical constitutive relation for a continuum material point of UMo fuels. Together with the irradiation induced creep model, the stress-update algorithm and consistent stiffness modulus for UMo fuels are derived for the nonlinear iterative solution of the stress and displacement fields in UMo monolithic fuel plates. Considering a heterogeneous irradiation condition, the user subroutines to define the thermo-mechanical constitutive relations in ABAQUS are programmed and verified, and the in-pile behavior simulation is carried out and the thermomechanical behavior evolution is analyzed.

\section{Material properties}

\subsection{Thermo-mechanical performance models of U-10Mo fuel}

In this section the thermo-mechanical parameters and models, including the models for calculating the radiation-induced swelling, the thermal expansion and the irradiation creep are presented.

\subsubsection{Thermal conductivity}

The thermal conductivity is given as a function of temperature [17],

$$
k=4.201 \times 10^{-2} T-1.049
$$

where $k$ in $\mathrm{W} /(\mathrm{K} \cdot \mathrm{m})$ is the coefficient of thermal conductivity, $T$ is the temperature in $\mathrm{K}$.

\subsubsection{Thermal expansion}

Ozaltun et al. listed a series of data for the coefficient of thermal expansion [17], the correlation between the coefficient of thermal expansion $\alpha^{T}$ and temperature $T$ was fitted as [15]

$\alpha^{T}=\left\{\begin{array}{c}3.0 \times 10^{-11} T^{2}-1.698 \times 10^{-8} T+1.395 \times 10^{-5} \\ T \leq 673 K \\ -5.0 \times 10^{-12} T^{2}+1.023 \times 10^{-8} T+1.148 \times 10^{-5} \\ T>673 K\end{array}\right\}$

Logarithmic strains are adopted in this study considering that large strains may occur in the UMo meat at higher burnup. The logarithmic thermal expansion strain components can be expressed as

$$
\varepsilon_{i j}^{t h}=\ln \left(1+\alpha^{T}\left(T-T_{0}\right)\right) \delta_{i j}
$$

where $T_{0}$ is the reference temperature with a value of $300 \mathrm{~K}, \delta_{i j}$ denotes the Kronecker delta.

\subsubsection{Irradiation-induced creep}

According to the creep constitutive theory [17], creep strain components can be calculated as

$$
d \varepsilon_{i j}^{c r}=\frac{3 s_{i j}}{2 \bar{\sigma}} d \bar{\varepsilon}^{c r}
$$

where, $s_{i j}$ depicts the deviatoric stress components at the current time, $\bar{\sigma}=\sqrt{\frac{3}{2} s_{i j} s_{i j}}$ is the Mises stress, $\varepsilon_{i j}^{c r}$ denotes the creep strain components, $\bar{\varepsilon}^{c r}$ is the equivalent creep strain.

For Eq.(4), using the trapezoidal integration for a time increment, we have

$$
\Delta \varepsilon_{i j}^{c r}=\frac{3\left(s_{i j}^{t+\Delta t}+s_{i j}^{t}\right)}{2\left(\bar{\sigma}^{t+\Delta t}+\bar{\sigma}^{t}\right)} \Delta \bar{\varepsilon}^{c r}
$$


which indicates that the creep strain increments depend on the stresses at time $t$ and time $t+\Delta t$.

The irradiation-induced uniaxial creep strain rate for UMo is presented as [7]

$$
\frac{d \varepsilon^{c r}}{d t}=B \sigma \dot{f}
$$

where, $B$ is the coefficient of creep rate equaling $300 \times 10^{-37} \mathrm{~m}^{3} / \mathrm{Pa} ; \sigma$ depicts the uniaxial stress in $\mathrm{Pa}$; $\dot{f}$ denotes the fission rate in fission $/\left(\mathrm{m}^{3} \mathrm{~s}\right)$, which means the nuclear fission number per second happens in a unit volume of fuel meat.

Similarly, the trapezoidal integration for Eq. (6) yields

$$
\Delta \bar{\varepsilon}^{c r}=\frac{B\left(\bar{\sigma}^{t+\Delta t}+\bar{\sigma}^{t}\right) \dot{f} \Delta t}{2}
$$

Substituting Eq.(7) into Eq.(5) yields

$$
\Delta \varepsilon_{i j}^{c r}=\frac{3\left(s_{i j}^{t+\Delta t}+s_{i j}^{t}\right)}{4} B \dot{f} \Delta t
$$

Obviously, $\Delta \varepsilon_{k k}^{c r}=0$.

\subsubsection{Irradiation-induced swelling}

Irradiation-induced swelling stems from fission gas swelling and fission solid swelling.

Here, an empirical equation to calculate the fission solid swelling was used [6]:

$$
\frac{\Delta V_{\text {solid }}}{V_{0}}=4.0 \times 10^{-29} f
$$

where $f$ in fission $/ \mathrm{m}^{3}$ describes the fission density, which describes the nuclear fission number occurred in a unit volume of fuel meat.

The fission gas model follows Yi Cui et al. [12] considering the recrystallization, hydrostatic pressure dependence and intergranular gas atom re-solution in grain scale. The swelling model in this study is based on the Booth model [18], in which the fuel grain is regarded as a spherical one. Fission gas swelling includes two parts, i.e., intragranular swelling and intergranular swelling.

Before recrystallization, the fission gas swelling can be calculated by the following equation:

$$
\frac{\Delta V_{\text {gas }}}{V}=\left.\left(\frac{\Delta V_{\text {intra }}}{V}\right)\right|_{r_{g r}}+\left.\left(\frac{\Delta V_{\text {inter }}}{V}\right)\right|_{r_{g r}}
$$

where the intragranular swelling can be expressed as [19]:

$$
\left.\left(\frac{\Delta V_{\text {intra }}}{V_{0}}\right)\right|_{r_{g r}}=\frac{4 \pi}{3} r_{b}^{3} c_{b}
$$

where, $r_{b}$ in $\mathrm{m}$ is the radius of the intragranular bubble; $c_{b}$ in $\mathrm{n} / \mathrm{m}^{3}$ is the fission gas bubble density, representing the number of fission gas bubbles in a unit volume of fuel meat. How to obtain the variables of $r_{b}$ and $c_{b}$ was presented in [12], which were calculated with the concentration of intergranular gas atoms.

The intergranular swelling takes the form as [20]:

$$
\left.\left(\frac{\Delta V_{\text {inter }}}{V_{0}}\right)\right|_{r_{g r}}=\frac{2 \pi R_{b}^{3} C_{b}}{r_{g r}}
$$

where, $C_{b}$ in $\mathrm{n} / \mathrm{m}^{2}$ is the intergranular bubble density, depicting the number of intergranular bubbles in a unit area of grain boundary; $R_{b}$ in m is the radius of the intergranular bubble; $r_{g r}$ in $\mathrm{m}$ is the grain radius.

Considering the influence of external hydrostatic pressure, the modified Van der Waals gas law is used [20]:

$$
\left(\frac{2 \gamma}{R_{b}}+p\right)\left(\frac{4 \pi R_{b}^{3}}{3}-h_{s} b_{v} N_{b}\right)=N_{b} k T
$$

where, $\gamma$ is the surface tension in $\mathrm{N} / \mathrm{m}, p$ is the external hydrostatic pressure in $\mathrm{Pa}, N_{b}=N / C_{b}$ is the gas atom number per intergranular bubble and $N$ depicts the concentration of intergranular fission gas atoms, $h_{s}$ is the fitting parameter to make the Van der Waals equation equivalent to the hard-sphere equation of state [19], $b_{v}$ is the Van der Waals constant for Xe. $N$ is calculated with the analytical solution [12], which was obtained through solving the governing equations for diffusion of fission gas atoms in the equivalent spherical grain, where re-solution of the intergranular fission gas atoms is considered.

So,

$$
\frac{\partial R_{b}}{\partial p}=\frac{h_{s} b_{v} N_{b} R_{b}^{2}-\frac{4 \pi}{3} R_{b}^{5}}{\frac{16 \pi}{3} \gamma R_{b}^{3}+4 \pi R_{b}^{4} p+2 \gamma h_{s} b_{v} N_{b}}
$$

with which the hydrostatic pressure can be solved through nonlinear iterations, as stated in the next section.

Considering Eq. (13) is a nonlinear equation, for a certain magnitude of $p$ the Newton's method to get $R_{b}$ should be performed.

After recrystallization, the original grain is divided into two parts including the recrystallized region and the unrecrystallized region. In the unrecrystallized region, the calculation of the gas swelling is similar to the calculation before recrystallization; while in the recrystallized region, it depends only on the intergranular swelling, because almost all fission gas atoms will transfer to the intergranular bubbles. The intergranular swelling can be expressed as [20]:

$$
\left.\left(\frac{\Delta V_{\text {inter }}}{V_{0}}\right)\right|_{r_{g r x}}=\frac{4 \pi R_{b x}^{3}}{3}\left(\frac{3 C_{b x}}{2 r_{g r x}}+\frac{1}{8 r_{g r x}^{3}}\right)
$$


where, $r_{g r x}$ is the recrystallized grain radius, $R_{b x}$ is the radius of the intergranular bubble in the recrystallized region; $C_{b x}$ is the intergranular bubble density [12].

Similar to that for $R_{b}$, according to the modified Van der Waals gas law, $\frac{\partial R_{b x}}{\partial p}$ can be obtained as:

$$
\frac{\partial R_{b x}}{\partial p}=\frac{h_{s} b_{v} N_{b x} R_{b x}^{2}-\frac{4 \pi}{3} R_{b x}^{5}}{\frac{16 \pi}{3} \gamma R_{b x}^{3}+4 \pi R_{b x}^{4} p+2 \gamma h_{s} b_{v} N_{b x}}
$$

with which the hydrostatic pressure can be calculated through nonlinear iterations, as described in the next section.

Subsequently, the fission gas swelling can be calculated according to

$$
\begin{aligned}
\frac{\Delta V_{\text {gas }}}{V}= & \left(1-V_{r}\right)\left[\left.\left(\frac{\Delta V_{\text {intra }}}{V}\right)\right|_{r_{g r}}+\left.\left(\frac{\Delta V_{\text {inter }}}{V}\right)\right|_{r_{g r}}\right] \\
& +\left.V_{r}\left(\frac{\Delta V_{\text {inter }}}{V}\right)\right|_{r_{g r x}}
\end{aligned}
$$

where, $V_{r}$ is the volume fraction of the recrystallized region [21].

So, the volumetric swelling strain can be expressed as:

$$
\frac{\Delta V}{V}=\frac{\Delta V_{\text {solid }}}{V}+\frac{\Delta V_{\text {gas }}}{V}
$$

Then, the logarithmic volumetric swelling strain can be obtained as:

$$
\theta^{s w}=\ln \left(1+\frac{\Delta V}{V}\right)
$$

Obviously, the logarithmic swelling strains are obtained as

$$
\varepsilon_{i j}^{s w}=\frac{1}{3} \delta_{i j} \theta^{s w}
$$

which depicts that the irradiation swelling strain in all directions is the same.

Some of used parameters are listed in Table.1, while the other parameters can be found in Ref. [12].

\subsubsection{Heat generation rate}

The heat generation in the UMo meat is proportional to the fission rate:

$$
q=c \cdot \dot{f}
$$

where, $q$ is the heat generation rate, $c=3.204 \times$ $10^{-11} \mathrm{~J} /$ fission is the generated heat energy for every fission event.

\subsection{Thermo-mechanical performance models of Al6061 cladding}

\subsubsection{Thermal conductivity}

The thermal conductivity is related to temperature [17], given as

$$
k=-1.77 \times 10^{-4} T^{2}+0.19 T+138.55
$$

where $273 \mathrm{~K} \leq T \leq 854 \mathrm{~K}$.

\subsubsection{Thermal expansion}

Based on some experimental data [17], we have the coefficient of thermal expansion $\alpha^{T}$ by polynomial fitting:

$$
\alpha^{T}=(0.9 T+2018) \times 10^{-8}
$$

where $373 \mathrm{~K} \leq T \leq 573 \mathrm{~K}$.

\subsubsection{The plasticity model}

The strain-hardening curve is described as:

$$
\sigma=K_{0} \varepsilon^{n}
$$

where, $\sigma$ in MPa is the true stress, $\varepsilon$ is the true strain, the strength coefficient $K_{0}=569.6 \mathrm{MPa}$ [7], the strainhardening exponent $n=0.13$ [7].

\section{Three-dimensional stress update algorithm and consistent stiffness modulus}

For the irradiation-induced thermo-mechanical coupling behavior in UMo monolithic fuel plates, the ABAQUS/STANDARD analysis is employed here. Owing to its nonlinearity, the whole solution process is divided into many increments. A sufficient number of equilibrium iterations are required to gain the convergent results for each increment, in which the three-dimensional stress update algorithms are used, and the consistent stiffness moduli $\frac{\partial \Delta \sigma}{\partial \Delta \varepsilon}$ need to be provided. The stress update algorithm and consistent stiffness moduli all depend on the three-dimensional incremental constitutive relation given as follows. 
Table 1: Parameters used in the simulation

\begin{tabular}{cccc}
\hline Parameters & Value & Unit & Source \\
\hline$\gamma$ & 1 & $\mathrm{~N} / \mathrm{m}$ & {$[11]$} \\
$b_{v}$ & $8.5 \times 10^{-29}$ & $\mathrm{~m}^{3} /$ atom & {$[12]$} \\
$h_{s}$ & 0.6 & - & {$[12]$} \\
$r_{g r x}$ & $0.25 \times 10^{-6}$ & $\mathrm{~m}$ & {$[12]$} \\
\hline
\end{tabular}

For a time increment $[t, t+\Delta t]$, the incremental constitutive relation in the co-rotational framework for an integration point is expressed as

$$
\Delta \sigma_{i j}=\sigma_{i j}^{t+\Delta t}-\sigma_{i j}^{t}=2 G \Delta \varepsilon_{i j}^{e}+\lambda \Delta \varepsilon_{k k}^{e} \delta_{i j}
$$

where, $\sigma_{i j}^{t}$ and $\sigma_{i j}^{t+\Delta t}$ separately represent the Cauchy stresses at time $t$ and $t+\Delta t ; \Delta \varepsilon_{i j}^{e}$ denotes the elastic strain increments; $G$ and $\lambda$ are the Lame constants, here they have no temperature dependence. For the temperaturedependent Lame constants, the incremental constitutive relations can be found in [22]. The stress update algorithms for the fuel meat will be mainly derived in the following.

\subsection{The stress update algorithm}

Considering the contributions of thermal expansion, irradiation-induced creep and irradiation swelling strains to the total strain increments, the elastic strain increments $\Delta \varepsilon_{i j}^{e}$ can be obtained as:

$$
\Delta \varepsilon_{i j}^{e}=\Delta \varepsilon_{i j}^{t o t a l}-\Delta \varepsilon_{i j}^{t h}-\Delta \varepsilon_{i j}^{c r}-\Delta \varepsilon_{i j}^{s w}
$$

where $\Delta \varepsilon_{i j}^{t o t a l}$ denotes the total logarithmic strain increments, the logarithmic creep strain increments $\Delta \varepsilon_{i j}^{c r}$ takes the form of Eq. (8). The logarithmic thermal expansion strain increments $\Delta \varepsilon_{i j}^{t h}$ can be shown as:

$$
\begin{aligned}
\Delta \varepsilon_{i j}^{t h}= & {\left[\ln \left(1+\alpha^{T+\Delta T}\left(T+\Delta T-T_{0}\right)\right)\right.} \\
& \left.-\ln \left(1+\alpha^{T}\left(T-T_{0}\right)\right)\right] \delta_{i j} \\
& =\delta_{i j} \ln \left[\frac{1+\alpha^{T+\Delta T}\left(T+\Delta T-T_{0}\right)}{1+\alpha^{T}\left(T-T_{0}\right)}\right]
\end{aligned}
$$

As mentioned above, the irradiation-induced swelling strains in all directions are equal. The logarithmic swelling strain increments $\Delta \varepsilon_{i j}^{s w}$ can be shown as:

$$
\begin{gathered}
\Delta \varepsilon_{i j}^{s w}=\frac{1}{3} \delta_{i j} \theta^{s w}\left(t+\Delta t, T+\Delta T, p^{t+\Delta t}\right)-\frac{1}{3} \delta_{i j} \theta^{s w}\left(t, T, p^{t}\right) \\
=\frac{1}{3} \delta_{i j}\left(\theta^{s w}\left(t+\Delta t, T+\Delta T, p^{t+\Delta t}\right)-\theta^{s w}\left(t, T, p^{t}\right)\right)
\end{gathered}
$$

Both the thermal expansion strain tensor and the swelling strain tensor will only lead to volumetric deformations, while the creep strain tensor results in no volumetric variations.
Substituting Eq. (26) into Eq. (25), we have

$$
\begin{aligned}
\sigma_{i j}^{t+\Delta t}= & \sigma_{i j}^{t}+2 G \Delta \varepsilon_{i j}^{e}+\lambda \Delta \varepsilon_{k k}^{e} \delta_{i j} \\
= & \sigma_{i j}^{t}+2 G\left(\Delta \varepsilon_{i j}^{t o t a l}-\Delta \varepsilon_{i j}^{t h}-\Delta \varepsilon_{i j}^{c r}-\Delta \varepsilon_{i j}^{s w}\right) \\
& +\lambda\left(\Delta \varepsilon_{k k}^{t o t a l}-\Delta \varepsilon_{k k}^{t h}-\Delta \varepsilon_{k k}^{s w}\right) \delta_{i j}
\end{aligned}
$$

It is known that the irradiation swelling and the irradiation creep strains are all dependent on the unknown stresses at $t+\Delta t$. In addition, the thermal expansion strains and the irradiation-induced swelling strains only rely on the spherical stress. Besides, the irradiation creep strains are directly determined by the deviatoric stress, as shown in Section 2.1.3. Thus, to update the stresses in the fuel meat, we can update separately its deviatoric stresses and spherical stresses. In the following, their update algorithms will be developed, respectively.

\subsubsection{Stress update algorithm for the spherical part}

Firstly, to update the spherical stresses, it's necessary to set $i=j$ in Eq. (29), and then multiply both sides by $-1 / 3$, we have

$$
\begin{aligned}
-\frac{\sigma_{k k}^{t+\Delta t}}{3}= & -\frac{\sigma_{k k}^{t}}{3}-\frac{2 G}{3}\left(\Delta \varepsilon_{k k}^{t o t a l}-\Delta \varepsilon_{k k}^{t h}-\Delta \varepsilon_{k k}^{s w}\right) \\
& -\lambda\left(\Delta \varepsilon_{k k}^{t o t a l}-\Delta \varepsilon_{k k}^{t h}-\Delta \varepsilon_{k k}^{s w}\right) \\
= & -\frac{\sigma_{k k}^{t}}{3}-\left(\frac{2 G}{3}+\lambda\right)\left(\Delta \varepsilon_{k k}^{t o t a l}-\Delta \varepsilon_{k k}^{t h}-\Delta \varepsilon_{k k}^{s w}\right) \\
= & -\frac{\sigma_{k k}^{t}}{3}-K\left(\Delta \varepsilon_{k k}^{t o t a l}-\Delta \varepsilon_{k k}^{t h}-\Delta \varepsilon_{k k}^{s w}\right)
\end{aligned}
$$

where, $K=\frac{2 G}{3}+\lambda$ is the bulk modulus.

Substitution of Eq. (27) and Eq. (28) into Eq. (30) yields

$$
\begin{aligned}
p= & -\frac{\sigma_{k k}^{t}}{3}-K\left(\Delta \varepsilon_{k k}^{\text {total }}-3 \ln \left(\frac{1+\alpha^{T+\Delta T}\left(T+\Delta T-T_{0}\right)}{1+\alpha^{T}\left(T-T_{0}\right)}\right)\right. \\
& \left.-\left(\theta^{s w}-\theta_{t}^{s w}\right)\right)
\end{aligned}
$$

where, the known $\theta_{t}^{s w}=\theta^{s w}\left(t, T, p^{t}\right)$, the unknown logarithmic volumetric strain at time $t+\Delta t \theta^{s w}$ depends on the unkown hydrostatic pressure, the temperature and the irradiation time as $\theta^{s w}\left(p^{t+\Delta t}, T+\Delta T, t+\Delta t\right)$, and $p=-\frac{\sigma_{k k}^{t+\Delta t}}{3}$ depicts the hydrostatic pressure to be determined. 
Eq. (31) is a nonlinear equation that the logarithmic volumetric swelling strain and the hydrostatic pressure satisfy. Using the hydrostatic-pressure-dependent equations for the logarithmic volumetric swelling strain, the Newton-Raphson iteration method is firstly adopted to get $p$ :

$$
\begin{gathered}
g(p)=p+\frac{\sigma_{k k}^{t}}{3}+K\left(\Delta \varepsilon_{k k}^{\text {total }}-3 \ln \left(\frac{1+\alpha^{T+\Delta T}\left(T+\Delta T-T_{0}\right)}{1+\alpha^{T}\left(T-T_{0}\right)}\right)\right. \\
\left.-\left(\theta^{s w}-\theta_{t}^{s w}\right)\right) \\
g^{\prime}(p)=1-K \frac{\partial \theta^{s w}}{\partial p} \\
p_{i+1}=p_{i}-\frac{g\left(p_{i}\right)}{g^{\prime}\left(p_{i}\right)}
\end{gathered}
$$

where, $p_{i}$ is the value of $p$ after the $i^{\text {th }}$ iteration. And it should be noted that $\theta^{s w}$ in $g\left(p_{i}\right)$ should be obtained with the iterative solution of Eq. (13) to get $R_{b}$ for a certain value of $p_{i}$.

In Eq. (33), $\frac{\partial \theta^{s w}}{\partial p}$ can be obtained by implementing partial derivative operations with respect to $p$ for the both sides of Eq. (19) together with Eq. (18), with the form described as

$$
\frac{\partial \theta^{s w}}{\partial p}=\frac{\frac{\partial}{\partial p}\left(\frac{\Delta V_{\text {gas }}}{V_{0}}\right)}{1+\frac{\Delta V_{\text {solid }}}{V_{0}}+\frac{\Delta V_{\text {gas }}}{V_{0}}}
$$

As given in Section 2.1.4, only the intergranular swelling is related to $p$. Before recrystallization, by combining Eq. (12) with Eq. (14) the partial derivative $\frac{\partial}{\partial p}\left(\frac{\Delta V_{\text {gas }}}{V_{0}}\right)$ can be obtained as

$$
\begin{aligned}
\frac{\partial}{\partial p}\left(\frac{\Delta V_{\text {gas }}}{V_{0}}\right) & =\frac{\partial}{\partial p}\left(\frac{\Delta V_{\text {inter }}}{V_{0}}\right) \\
& =\frac{6 \pi R_{b}^{2} C_{b}}{r_{g r}} \frac{h_{s} b_{v} N_{b} R_{b}^{2}-\frac{4 \pi}{3} R_{b}^{5}}{\frac{16 \pi}{3} \gamma R_{b}^{3}+4 \pi R_{b}^{4} p+2 \gamma h_{s} b_{v} N_{b}}
\end{aligned}
$$

Then using the partial derivative $\frac{\partial \partial^{s w}}{\partial p}, p$ before recrystallization will be worked out and $\theta^{\text {sw }}$ can be determined simultaneously.

While during the recrystallization, the partial derivative $\frac{\partial}{\partial p}\left(\frac{\Delta V_{\text {gas }}}{V_{0}}\right)$ can be derived by using Eq. (14), Eq. (15) and Eq. (16) as

$$
\begin{aligned}
& \frac{\partial}{\partial p}\left(\frac{\Delta V_{g a s}}{V_{0}}\right)=\left(1-V_{r}\right) \frac{6 \pi R_{b}^{2} C_{b}}{r_{g r}} \frac{\partial R_{b}}{\partial p} \\
& +4 \pi R_{b x}^{2} V_{r}\left(\frac{3 C_{b x}}{2 r_{g r x}}+\frac{1}{8 r_{g r x}^{3}}\right) \frac{\partial R_{b x}}{\partial p} \\
= & \left(1-V_{r}\right) \frac{6 \pi R_{b}^{2} C_{b}}{r_{g r}} \frac{h_{s} b_{v} N_{b} R_{b}^{2}-\frac{4 \pi}{3} R_{b}^{5}}{\frac{16 \pi}{3} \gamma R_{b}^{3}+4 \pi R_{b}^{4} p+2 \gamma h_{s} b_{v} N_{b}}
\end{aligned}
$$

$$
\begin{gathered}
+4 \pi R_{b x}^{2} V_{r}\left(\frac{3 C_{b x}}{2 r_{g r x}}+\frac{1}{8 r_{g r x}^{3}}\right) \\
\frac{h_{s} b_{v} N_{b x} R_{b x}^{2}-\frac{4 \pi}{3} R_{b x}^{5}}{\frac{16 \pi}{3} \gamma R_{b x}^{3}+4 \pi R_{b x}^{4} p+2 \gamma h_{s} b_{v} N_{b x}}
\end{gathered}
$$

Also, $p$ and $\theta^{s w}$ during the recrystallization can be obtained through nonlinear iterations. Considering $p=$ $-\frac{\sigma_{k k}^{t+\Delta t}}{3}$, so the spherical stresses at time $t+\Delta t$ can be obtained.

\subsubsection{Stress update algorithm for the deviatoric part}

As for the deviatoric stresses $s_{i j}^{t+\Delta t}$, we introduce the trial stresses $\sigma_{i j}^{p r}$ which refers to the stresses without involving the contribution of irradiation creep strain increments, then we have

$$
\sigma_{i j}^{t+\Delta t}=\sigma_{i j}^{p r}-2 G \Delta \varepsilon_{i j}^{c r}
$$

As is known that the creep strain tensor is a deviatoric tensor, so

$$
s_{i j}^{t+\Delta t}=s_{i j}^{p r}-2 G \Delta \varepsilon_{i j}^{c r}
$$

where, $s_{i j}^{p r}$ is the deviatoric part of $\sigma_{i j}^{p r}$.

Substituting Eq. (8) into Eq. (39), we have

$$
s_{i j}^{t+\Delta t}=s_{i j}^{p r}-\frac{3}{2} G B \dot{f} \Delta t\left(s_{i j}^{t+\Delta t}+s_{i j}^{t}\right)
$$

So,

$$
s_{i j}^{t+\Delta t}=\frac{s_{i j}^{p r}-\frac{3}{2} G B \dot{f} \Delta t \cdot s_{i j}^{t}}{1+\frac{3}{2} G B \dot{f} \Delta t}
$$

where, $s_{i j}^{p r}$ can be determined by the obtained stresses without considering the irradiation creep strain increments. As mentioned above, the increments of thermal expansion and irradiation swelling will not contribute to the deviatoric stresses. Thus, the deviatoric stresses in the fuel meat can be simply updated.

As a result, the Cauchy stress tensor can be updated with the contributions of the spherical part and the deviatoric part.

The flow chart of the stress-update algorithm is shown in Fig. 1. In every time increment $[t, t+\Delta t]$, the swelling strain is firstly calculated with the hydrostatic pressure at time $t$, after which in every iteration step the hydrostatic pressure $p$ at time $t+\Delta t$ is obtained according to Eq. (34). It is noted that for a certain hydrostatic pressure, the radius of intergranular bubbles is obtained with Newton iteration method based on Eq. (13). As depicted in the flow chart, when the irradiation swelling strain and hydrostatic pressure $p$ are convergent, the deviatoric stress components at time $t+\Delta t$ can be obtained according to Eq. (41), with the creep effect taken into account. Finally, $\sigma_{i j}^{t+\Delta t}=s_{i j}^{t+\Delta t}-p \delta_{i j}$, the stress update is finished. 


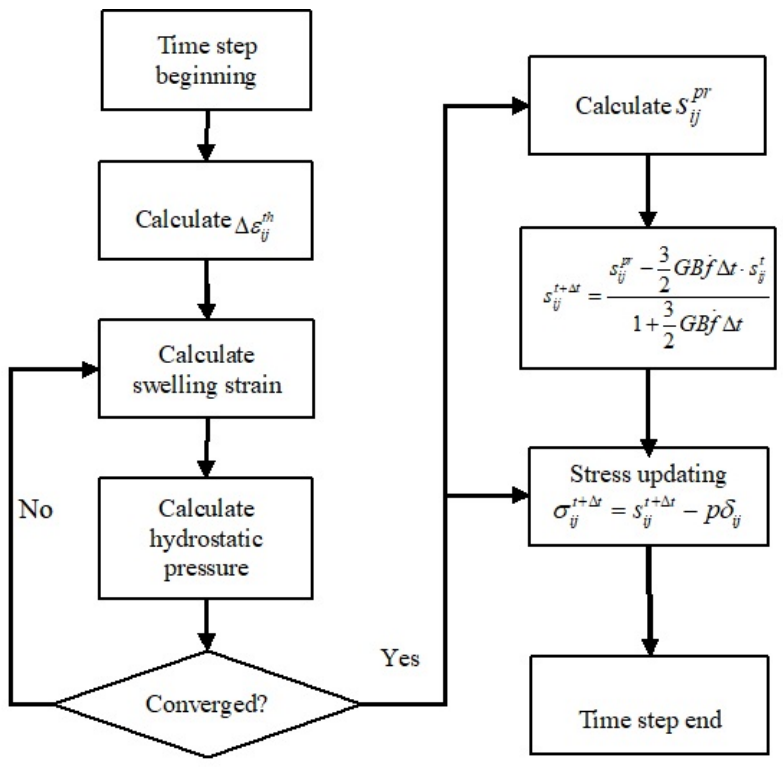

Figure 1: Flow chart of stress-update algorithm

\subsection{Consistent stiffness modulus}

In nonlinear FEM calculations, the consistent stiffness modulus $C_{i j k l}=\frac{d \Delta \sigma_{i j}}{d \Delta \varepsilon_{k l}^{\text {tot }}}$ is needed for the equilibrium interation. In this section, the moduli for the fuel meat will be mainly derived.

Considering irradiation-induced creep and hydrostatic-pressure-dependent irradiation swelling in the material point of the fuel meat, the consistent stiffness modulus will be developed according to the incremental mechanical constitutive relation in the following.

Substitution of Eq. (8) into Eq. (29) yields

$$
\begin{aligned}
\Delta \sigma_{i j}= & 2 G\left(\Delta \varepsilon_{i j}^{t o t a l}-\Delta \varepsilon_{i j}^{t h}-\Delta \varepsilon_{i j}^{c r}-\Delta \varepsilon_{i j}^{s w}\right) \\
& +\lambda\left(\Delta \varepsilon_{k k}^{t o t a l}-\Delta \varepsilon_{k k}^{t h}-\Delta \varepsilon_{k k}^{s w}\right) \delta_{i j} \\
= & 2 G \Delta \varepsilon_{i j}^{t o t a l}+\lambda \Delta \varepsilon_{k k}^{t o t a l} \delta_{i j}-\frac{3}{2} G\left(s_{i j}^{t+\Delta t}+s_{i j}^{t}\right) B \dot{f} \Delta t \\
& -2 G\left(\Delta \varepsilon_{i j}^{t h}+\Delta \varepsilon_{i j}^{s w}\right)-\lambda\left(\Delta \varepsilon_{k k}^{t h}+\Delta \varepsilon_{k k}^{s w}\right) \delta_{i j}
\end{aligned}
$$

where, $\Delta \sigma_{i j}=\sigma_{i j}^{t+\Delta t}-\sigma_{i j}^{t}$.

Set $H^{\star}=\frac{3}{2} G B \dot{f} \Delta t$, then performing differentiation on both sides of Eq. (42) yields

$$
\begin{gathered}
d\left(\Delta \sigma_{i j}\right)=2 G d\left(\Delta \varepsilon_{i j}^{\text {total }}\right)+\lambda d\left(\Delta \varepsilon_{k k}^{t o t a l}\right) \delta_{i j}-H^{\star} d s_{i j}^{t+\Delta t} \\
-2 G d\left(\Delta \varepsilon_{i j}^{s w}\right)-\lambda d\left(\Delta \varepsilon_{k k}^{s w}\right) \delta_{i j}
\end{gathered}
$$

Considering $s_{i j}^{t+\Delta t}=\sigma_{i j}^{t+\Delta t}-\frac{1}{3} \sigma_{k k}^{t+\Delta t} \delta_{i j}$, then

$$
d s_{i j}^{t+\Delta t}=d \Delta \sigma_{i j}-\frac{1}{3} d \Delta \sigma_{k k} \delta_{i j}
$$

$$
=d \Delta \sigma_{i j}-K d\left(\Delta \varepsilon_{k k}^{\text {total }}\right) \delta_{i j}+K d\left(\Delta \varepsilon_{k k}^{s w}\right) \delta_{i j}
$$

Substituting Eq. (44) into Eq. (43), we have

$$
\begin{gathered}
d\left(\Delta \sigma_{i j}\right)=\frac{2 G}{1+H^{*}} d\left(\Delta \varepsilon_{i j}^{\text {total }}\right)+\frac{\lambda+H^{*} K}{1+H^{*}} d\left(\Delta \varepsilon_{k k}^{\text {total }}\right) \delta_{i j} \\
-\frac{2 G}{1+H^{*}} d\left(\Delta \varepsilon_{i j}^{S W}\right)-\frac{\lambda+H^{*} K}{1+H^{*}} d\left(\Delta \varepsilon_{k k}^{S W}\right) \delta_{i j}
\end{gathered}
$$

Substitution of Eq. (20) into Eq. (45) yields

$$
\begin{aligned}
d\left(\Delta \sigma_{i j}\right)= & \frac{2 G}{1+H^{\star}} d\left(\Delta \varepsilon_{i j}^{\text {total }}\right)+\frac{\lambda+H^{\star} K}{1+H^{\star}} d\left(\Delta \varepsilon_{k k}^{\text {total }}\right) \delta_{i j} \\
& -\frac{2 G}{3\left(1+H^{\star}\right)} d\left(\theta^{s w}\right) \delta_{i j}-\frac{\lambda+H^{\star} K}{1+H^{\star}} d\left(\theta^{s w}\right) \delta_{i j} \\
= & \frac{2 G}{1+H^{\star}} d\left(\Delta \varepsilon_{i j}^{\text {total }}\right)+\frac{\lambda+H^{\star} K}{1+H^{\star}} d\left(\Delta \varepsilon_{k k}^{\text {total }}\right) \delta_{i j} \\
& -K d\left(\theta^{s w}\right) \delta_{i j}
\end{aligned}
$$

Differentiation on both sides of Eq. (31) yields

$$
d p=-K d\left(\Delta \varepsilon_{k k}^{\text {total }}\right)+K d\left(\theta^{s w}\right)=-K d\left(\Delta \varepsilon_{m m}^{\text {total }}\right)+K d\left(\theta^{s w}\right)
$$

Eq. (47) is related to the total strain. Then take the partial derivative with respect to the total strain increment $\Delta \varepsilon_{k l}^{t o t a l}$ on both sides of Eq. (47), we have

$\frac{d p}{d \Delta \varepsilon_{k l}^{\text {total }}}=-K \frac{d \Delta \varepsilon_{m m}^{\text {total }}}{d \Delta \varepsilon_{k l}^{\text {total }}}+K \frac{d \theta^{\text {sw }}}{d \Delta \varepsilon_{k l}^{\text {total }}}=-K \delta_{k l}+K \frac{d \theta^{\text {sw }}}{d \Delta \varepsilon_{k l}^{\text {total }}}$

Substituting $\frac{d p}{d \Delta \varepsilon_{k l}^{\text {total }}}=\frac{d p}{d \theta^{\mathrm{sw}}} \frac{d \theta^{\mathrm{sw}}}{d \Delta \varepsilon_{k l}^{\text {total }}}$ into Eq. (48), we obtain

$$
\frac{d \theta^{s w}}{d \Delta \varepsilon_{k l}^{\text {total }}}=-\frac{K h^{s w}}{1-K h^{s w}} \delta_{k l}
$$

where, $h^{s w}=\frac{d \theta^{s w}}{d p}$.

Taking the partial derivative with respect to the total strain increment $\Delta \varepsilon_{k l}^{\text {total }}$ on both sides of Eq. (46) yields

$$
\begin{aligned}
C_{i j k l}^{\text {swcr }}= & \frac{d\left(\Delta \sigma_{i j}\right)}{d\left(\Delta \varepsilon_{k l}^{\text {total }}\right)} \\
= & \frac{G}{1+H^{\star}} \frac{d\left(\Delta \varepsilon_{i j}^{\text {total }}+\Delta \varepsilon_{j i}^{\text {total }}\right)}{d\left(\Delta \varepsilon_{k l}^{\text {total }}\right)} \\
& +\frac{\lambda+H^{\star} K}{1+H^{\star}} \frac{d\left(\Delta \varepsilon_{m m}^{\text {total }}\right)}{d\left(\Delta \varepsilon_{k l}^{\text {total }}\right)} \delta_{i j}-K \frac{d\left(\theta^{\text {sw }}\right)}{d\left(\Delta \varepsilon_{k l}^{\text {total }}\right)} \delta_{i j} \\
= & \frac{G}{1+H^{\star}}\left(\delta_{i k} \delta_{j l}+\delta_{j k} \delta_{i l}\right)+\frac{\lambda+H^{\star} K}{1+H^{\star}} \delta_{i j} \delta_{k l} \\
& +K \frac{K h^{s w}}{1-K h^{s w}} \delta_{i j} \delta_{k l}=\lambda^{\star} \delta_{i j} \delta_{k l}+G^{\star}\left(\delta_{i k} \delta_{j l}+\delta_{j k} \delta_{i l}\right)
\end{aligned}
$$

where, $\lambda^{\star}=\frac{\lambda+H^{\star} K}{1+H^{\star}}+\frac{K^{2} h^{s w}}{1-K h^{s w}}, G^{\star}=\frac{G}{1+H^{\star}}$. 


\section{Finite element modeling}

To study the in-pile thermo-mechanical coupling behavior of the UMo monolithic fuel plates under heterogeneous irradiation, a FEM model matching the RERTR-9A test for L1P04A [7] is built in commercial software ABAQUS.

For the nuclear fuels, the mechanical constitutive relation is highly complex and location-dependent, it is not easy to be introduced into the finite element simulation through the graphical user interface of commercial software. UMAT in ABAQUS is a convenient user subroutine to define the special three-dimensional mechanical constitutive relationship. In this study, UMAT is written according to the developed stress update algorithm and consistent stiffness modulus mentioned in Section 3. UMATHT is programmed according to the thermal constitutive relation describing the relation between the thermal flux and temperature gradient.

\subsection{Heterogeneous irradiation condition}

The irradiation condition in the research and test reactors is considered, and according to [7] the fission rate in the fuel meat of the fuel plate L1P04A is fitted as

$$
\begin{gathered}
\dot{f}=\dot{f}_{0} \cdot \beta \\
\beta=3.567 \times 10^{-5} y^{4}-1.672 \times 10^{-3} y^{3}+3.026 \times 10^{-2} y^{2} \\
-0.2752 y+1.900
\end{gathered}
$$

where $\beta$ shows the spatial heterogeneous distribution feature of the fission rate, and $y$ depicts the distance away from the heavily irradiated width-direction edge of the UMo meat, which is close to the reactor core, and $\dot{f}_{0}$ is a constant being $6.0 \times 10^{20}$ fission $/ \mathrm{m}^{3} \mathrm{~s}$. The heavily irradiated fuel edge is corresponding to the origin of the path in Fig. 3(a).

\subsection{Finite element model}

In a plate-type monolithic fuel structure, the fuel meat is metallurgically bonded with the metal cladding. The considered UMo monolithic fuel plate has dimensions of $100.0 \times 25.0 \times 1.4 \mathrm{~mm}$ with a $82.6 \times 19.0 \times 0.25 \mathrm{~mm}$-sized fuel meat. Due to the symmetry in geometry and loading, the finite element model only needs to consider a $1 / 4$ part of the full-sized monolithic plate, as shown in Fig. 2, the upper surface depicts the through-thickness symmetrical plane of the fuel plate. Using the reduced integration element
C3D8RT with hourglass control, the finite element model is discretized by different mesh designs to study its convergence. From the plate width center to the interface between the fuel meat and cladding, the meshes are gradually refined. The mesh grid density depends on the maximum element size and minimum element size. The numbers of nodes and elements for each mesh design are shown in Table 2. The Mises stresses along the path shown in Fig. 3(a) are selected to verify the convergence. As illustrated in Fig. 3(b), the Mises stress at the middle of the path converged when the maximum element length decreases from $1 \mathrm{~mm}$ to $0.5 \mathrm{~mm}$, while the stresses at the edge changes little when the minimum element length decreases from $0.1 \mathrm{~mm}$ to $0.05 \mathrm{~mm}$. Mesh 4 in Table 2 is used in the FEM simulation, as illustrated in Fig. 3(c).

The thermo-mechanical constitutive relations for the fuel meat and cladding are defined with the user subroutines.
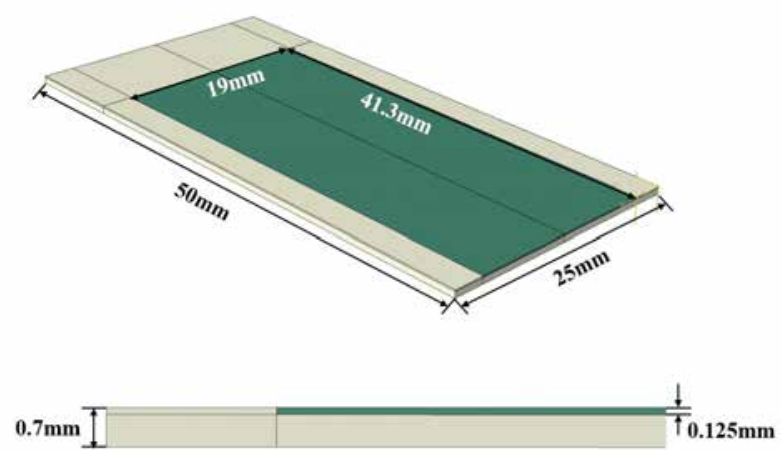

(a)

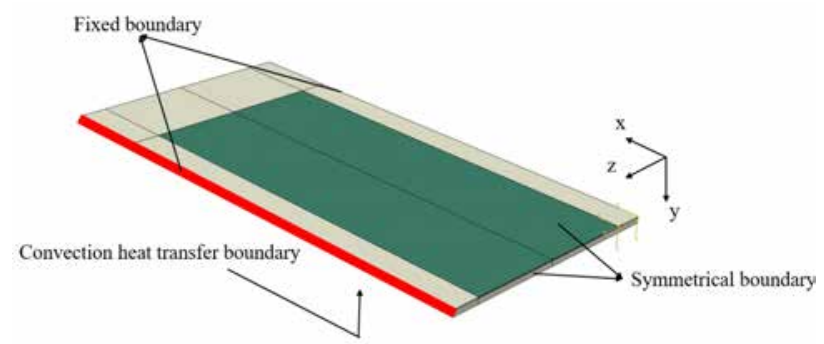

(b)

Figure 2: a) Finite element model and b) boundary conditions 
Table 2: Different mesh designs

\begin{tabular}{ccccc}
\hline Mesh design & $\begin{array}{c}\text { Maximum } \\
\text { element } \\
\text { length(mm) }\end{array}$ & $\begin{array}{c}\text { Minimum element } \\
\text { length(mm) }\end{array}$ & Nodes & Elements \\
\hline Mesh 1 & 0.5 & 0.2 & 175060 & 151164 \\
Mesh 2 & 0.75 & 0.1 & 177354 & 153140 \\
Mesh 3 & 0.6 & 0.1 & 236386 & 204776 \\
Mesh 4 & 0.5 & 0.1 & 300532 & 261306 \\
Mesh 5 & 1 & 0.05 & 179648 & 155116 \\
\hline
\end{tabular}

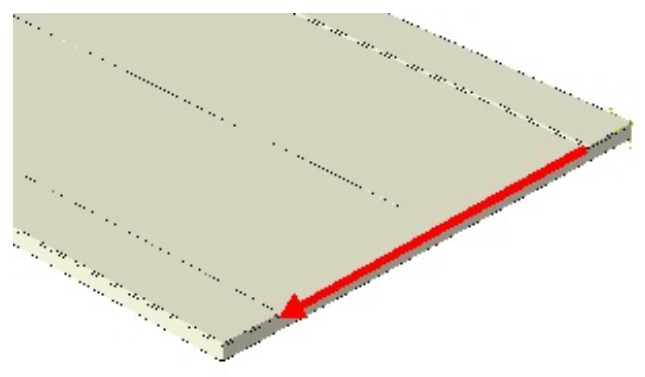

(a)

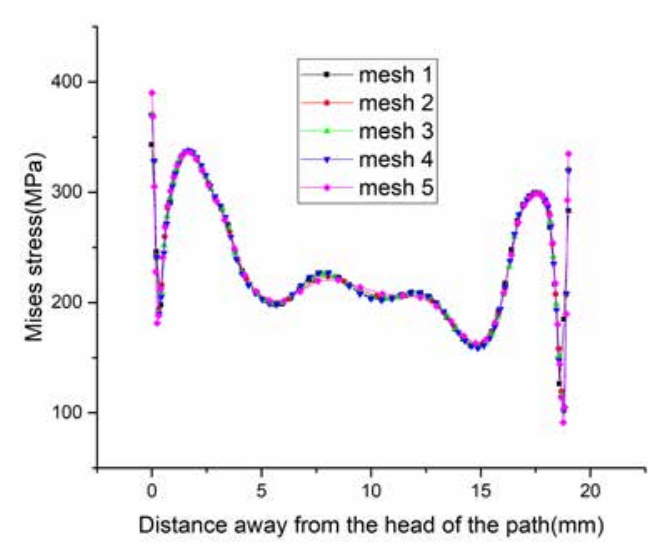

(b)

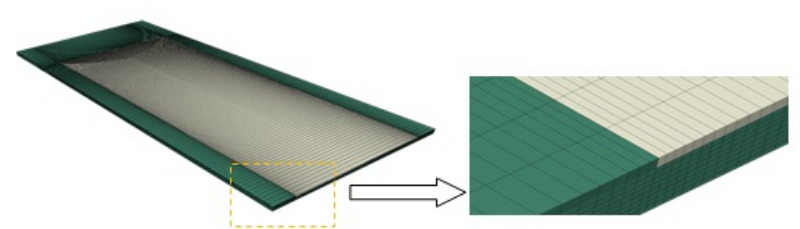

(c)

Figure 3: a) The output path; b) Mises stress results along the path and (c) Mesh grids used in the simulations

\subsection{Thermo-mechanical boundary conditions}

\subsubsection{Thermal boundary conditions}

As illustrated in Fig. 2(b), the convection heat transfer boundary refers to the lower surface of the finite element model, which meets the convection boundary condition: $-k\left(\frac{\partial T}{\partial n}\right)=h\left(T-T_{f}\right)$, where the temperature of the coolant $T_{f}=323 \mathrm{~K}$. The heat transfer coefficient $h$ is related to parameters such as the heat transfer area and Reynolds number [23-25]. In this study, the heat transfer coefficient $h=0.035 \mathrm{~W} / \mathrm{mm}^{2} \mathrm{~K}$;

The other surfaces satisfy the heat insulation condition, that is, $-k\left(\frac{\partial T}{\partial n}\right)=0$.

\subsubsection{Mechanical boundary conditions}

(1) Two symmetrical boundary conditions are respectively set on the surfaces, shown in Fig. 2(b);

(2) The side surfaces are fixed to restrain the rigid body movement, as shown in Fig. 2(b);

(3) The other surfaces are set as free boundaries because the pressure of the coolant is small [26].

\section{Results and Discussion}

\subsection{Validation and Verification of the models}

\subsubsection{Validation of the developed models}

To validate the developed models and algorithms, the calculated thickness variations for the UMo fuel meat are compared with the measured data from RERTR-9A experiment [7].

From Fig. 4(b) it can be seen that the obtained numerical results for the relative variations of fuel meat thick- 


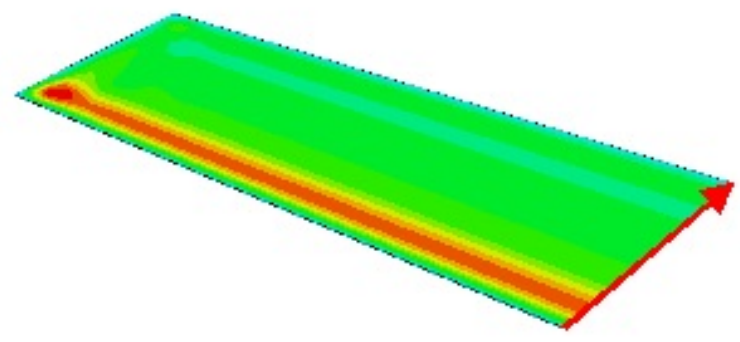

(a)

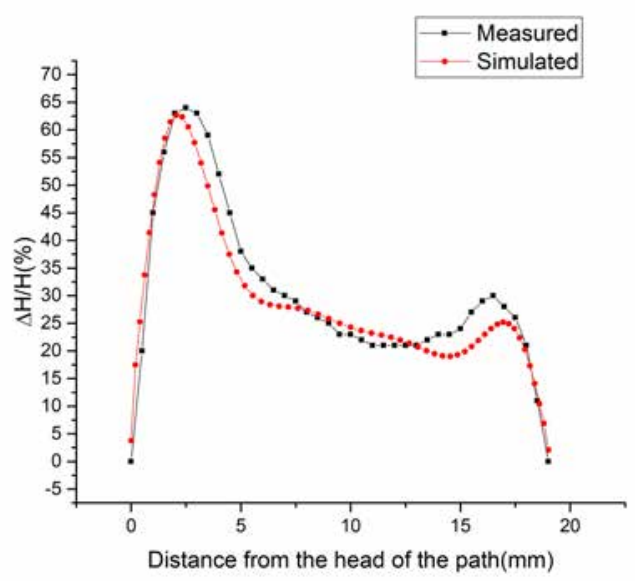

(b)

Figure 4: a) The output path; b) validation of the simulated fuel swelling

ness matches compariably well with the experimental results. And compared with the predicted results based on the swelling empirical formulas [7], the numerical results in this study agree better with the experimental ones near the heavily irradiated edge. This is for the reason that large hydrostatic pressures undergo at these areas, which will lead to smaller local fission gas swelling. As a result, the developed models and algorithms in this study are effective.

\subsubsection{Verification of UMAT and UMATHT}

To verify the accuracy and effectiveness of UMAT and UMATHT, the calculation results in the UMo monolithic plate are analyzed.

According to the logarithmic elastic strain components calculated by ABAQUS, the "theoretical" Cauchy stresses can be calculated by using the elastic constitutive relation.
Comparing the "theoretical" Cauchy stresses with the numerical results of the Cauchy stresses outputted by ABAQUS, the elastic constitutive relation can be verified. Fig. 5 gives the stress component $\sigma_{11}$ on the $98^{\text {th }}$ day. One can see that the numerical results are in good agreement with the "theoretical" ones, in fact, all of the other stress components also obey the elastic constitutive relations, which demonstrate that the elastic constitutive relations in the meat and cladding are correctly defined in UMAT.

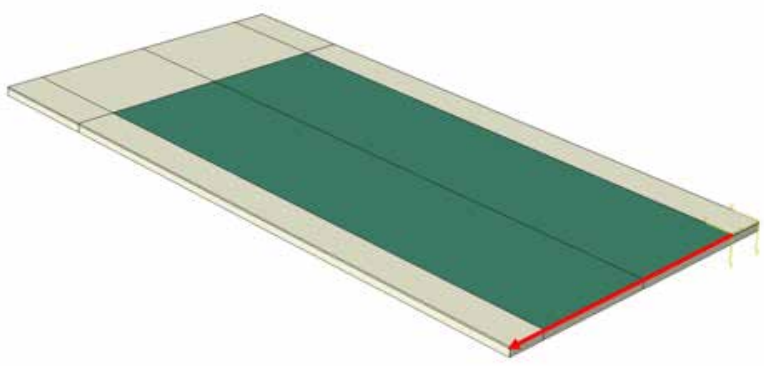

(a)

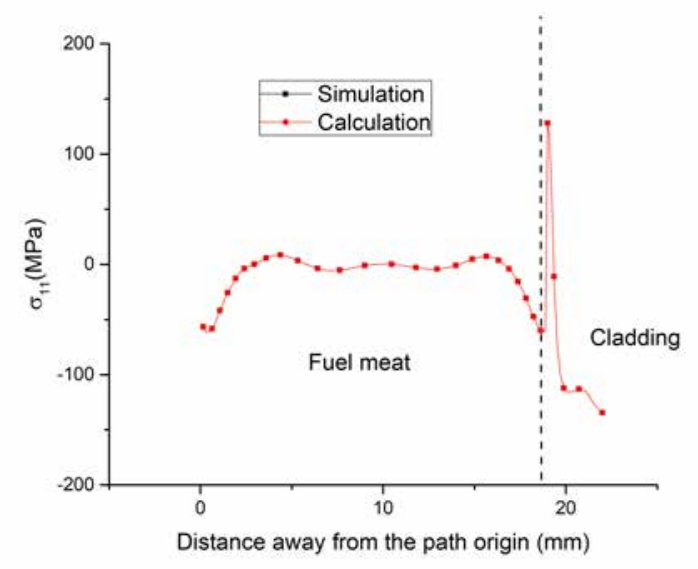

(b)

Figure 5: Verification of elastic constitutive relation

Using Eq. (2), the thermal expansion coefficient can be calculated according to the temperature $T+\Delta T$, with which substituted into Eq. (3) the "theoretical" logarithmic thermal expansion strain along one direction can be determined; comparing it with the logarithmic thermal expansion strain output by ABAQUS, the correct definition of thermal expansion strain can be verified.

Fig. 6 shows the comparison between the "theoretical" results and the numerical results on the $98^{\text {th }}$ day along the output path in Fig. 6, which indicates that they fit well with each other. So, it can be concluded that the thermal expan- 
sion strains in the meat and cladding are correctly defined in UMAT.

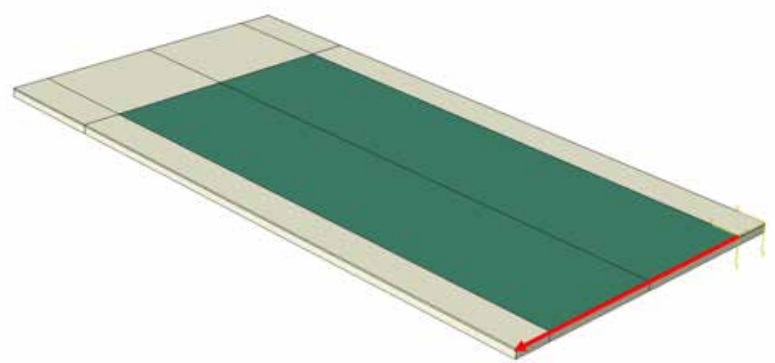

(a)

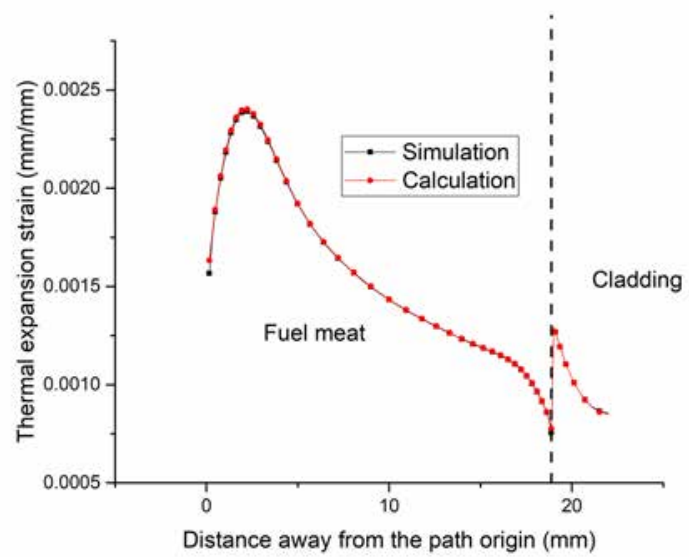

(b)

Figure 6: The verification of thermal expansion

The heat flux obeys:

$$
q=-k \nabla T
$$

which is introduced into the FEM simulation by the subroutine UMATHT.

According to the temperature $T+\Delta T$ on the $11^{\text {th }}$ day, the thermal conductivity can be calculated; using the outputted $\frac{\partial T}{\partial y}$ defined as a state variable in the UMATHT, then the "theoretical" heat flux $q_{y}$ is calculated with Eq. (53); comparing it with the numerical results of the heat flux output by ABAQUS, the defined thermal conductivity will be verified.

The comparison between the heat flux obtained above by Eq. (53) and the numerical one on the $98^{\text {th }}$ day can be found in Fig. 7, which shows that these results agree well with each other. Consequently, the thermal conductivities of the fuel meat and cladding are well defined in UMATHT and the corresponding programs are written correctly.

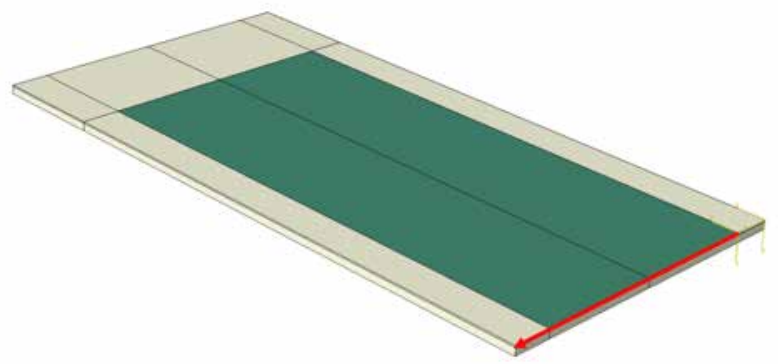

(a)

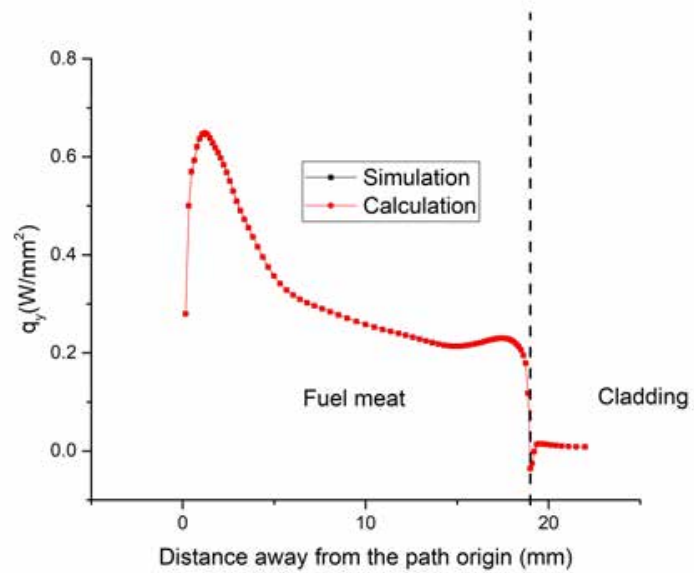

(b)

Figure 7: Verification of heat flux

The correctness is confirmed for introduction of the hydrostatic-pressure-dependent irradiation swelling into the mechanical constitutive relation, as shown in Fig. 8. The numerical results for the swelling strains on the $98^{\text {th }}$ day are obtained from the output files of ABAQUS. The "theoretical" true swelling strain including the fission solid swelling and fission gas swelling is obtained as

$$
\varepsilon^{s w}=\frac{1}{3} \ln \left(1+\frac{\Delta V}{V}\right)
$$

while $\frac{\Delta V}{V}$ can be obtained with Eq. (9), (11), (12), (15) and (17) based on the fem-obtained bubble radius. One can find that the "theoretical" results are consistent with the numerical results, and the swelling values are lower near the heavily irradiated edge due to the large hydrostatic pressure there, which can be found in Section 5.2.3.

The "theoretical" Mises stress $\bar{\sigma}^{t+\Delta t}$ can be determined by [22]:

$$
\bar{\sigma}^{t+\Delta t}=K_{0}\left(\bar{\varepsilon}_{p}^{t+\Delta t}+\frac{\bar{\sigma}^{t+\Delta t}}{E}\right)^{n}
$$




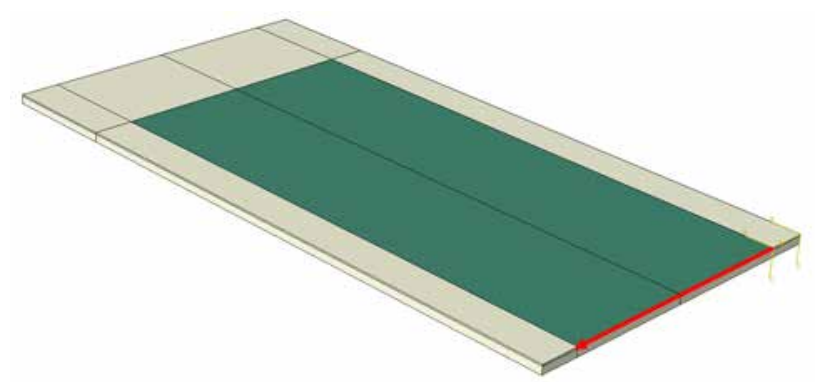

(a)

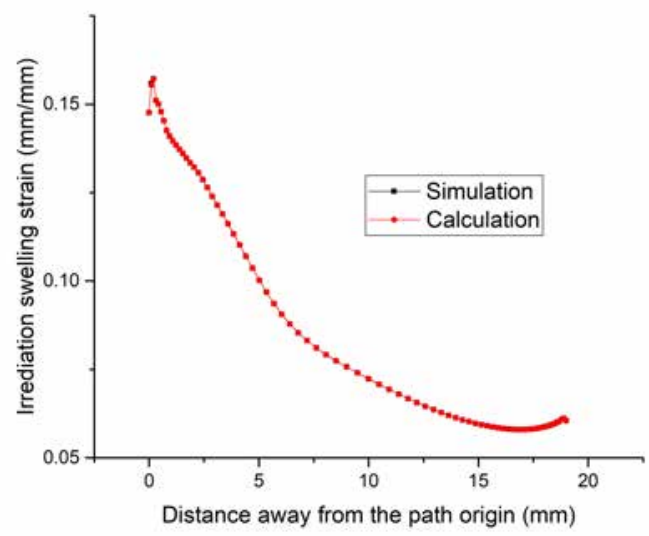

(b)

Figure 8: Verification of irradiation swelling strains

where, $\bar{\varepsilon}_{p}^{t+\Delta t}$ is output by ABAQUS. The theoretical results of $\bar{\sigma}^{t+\Delta t}$ are calculated through nonlinear iterative solution of Eq. (55)

Fig. 9 gives the "theoretical" results of the Mises stress calculated by the equivalent elasto-plastic strains $\bar{\varepsilon}_{p}^{t+\Delta t}+$ $\frac{\bar{\sigma}^{t+\Delta t}}{E}$. One can see that the points locate at the hardening curve, which depicts that the Mises stresses and the equivalent elasto-plastic strain obey the functional relation of the hardening curve. It is noted that the investigated point is experiencing the plastic loading process. As a result, the plasticity model is verified to be correctly involved in the mechanical constitutive relation for the cladding.

The "theoretical" equivalent creep strain $\bar{\varepsilon}_{c r}^{t+\Delta t}$ is calculated using Eq. (7) with substitution of $\bar{\sigma}^{t+\Delta t}, \bar{\sigma}^{t}, \dot{f}$ and $\bar{\varepsilon}_{c r}^{t}$ output by ABAQUS, where the Mises stress $\bar{\sigma}=\sqrt{\frac{3}{2} s_{i j} s_{i j}}$. As shown in Section 3.1.2, the deviatoric stresses $s_{i j}$ depends on the equivalent creep strain. The "theoretical" results on the $1.1^{\text {th }}$ day are compared with the numerical ones from ABAQUS, as depicted in Fig. 10. One can observe that both results are consistent with each other, thus the irradiation induced creep in the meat is well involved in UMAT.

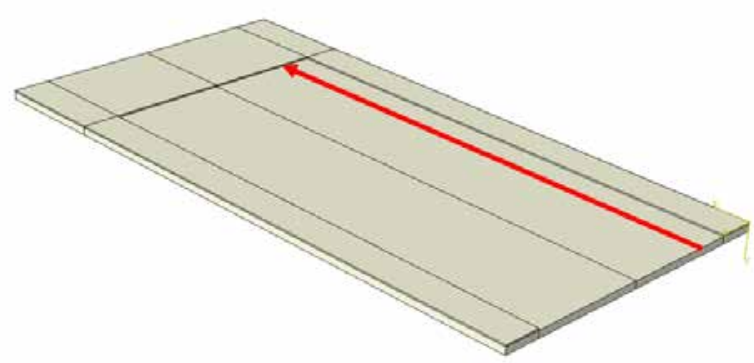

(a)

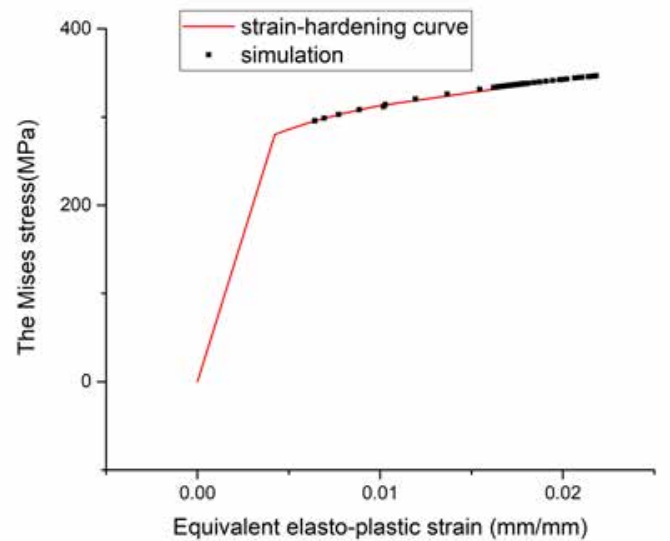

(b)

Figure 9: Verification of plasticity constitutive relation

Simultaneously, it is confirmed that the calculation of the deviatoric stresses is correct.

\subsection{Discussion of the thermo-mechanical behavior in the UMo monolithic fuel plate}

Thermo-mechanical behavior in the monolithic plate is simulated under an irradiation history of 98 days. The spatial distributions and temporal evolutions of temperature, strain and stress fields are analyzed in this section.

\subsubsection{Temperature field}

Fig. 11 shows the distribution of temperature on the $98^{\text {th }}$ day. It can be seen that the temperature in the fuel meat is much higher than that in the cladding, and the highest temperature of $487.9 \mathrm{~K}$ appears at the location near the heavily irradiated fuel edge. According to the experimental result, the temperature at the middle of the fuel is about 


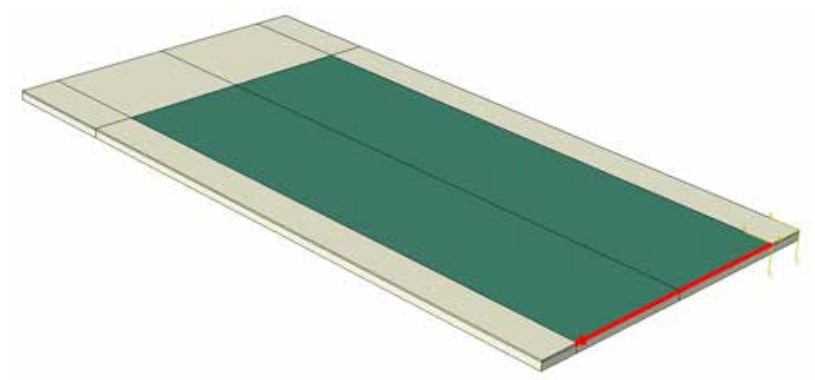

(a)

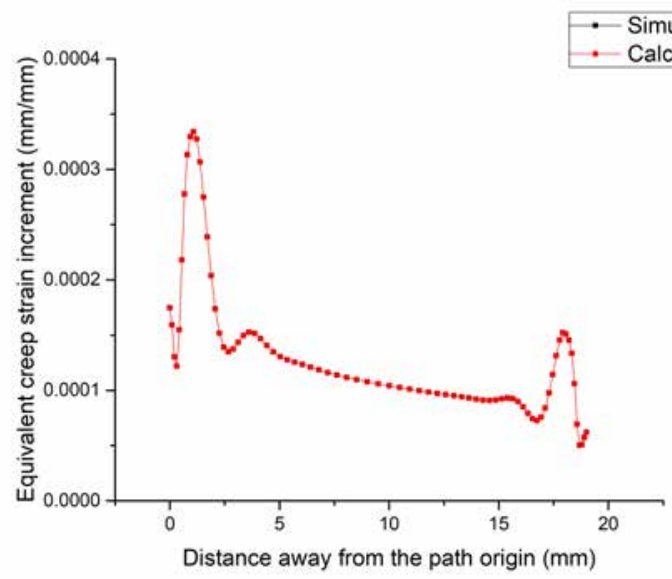

(b)

Figure 10: Verification of fission-induced creep effect

$425 \mathrm{~K}[7]$, and in this simulation the predicted temperature is 423K, which matches well with the experimental result. The distribution and evolution of temperatures along Path 1 (depicted in Fig. 11) are plotted in Fig. 12. As is known, the maximum fission rate takes place at the heavily irradiated fuel edge corresponding to the starting point of Path 1. One can see clearly that the highest temperature exists in the position a distance away from the starting point of the Path 1, which results from the fact that the cladding has a very high thermal conductivity and can effectively remove the generated heat in the fuel meat near the meat/cladding interface. Besides, it can be observed that the highest temperature increases remarkably with the irradiation time. The highest temperature on the $98^{\text {th }}$ day achieves a magnitude about $61.7 \mathrm{~K}$ higher than that on the $1.1^{\text {th }}$ day. It is the main reason that the fuel meat around the peak temperature zone is thickened with the irradiation time, which is reflected by the strain results in Section 5.2.2.
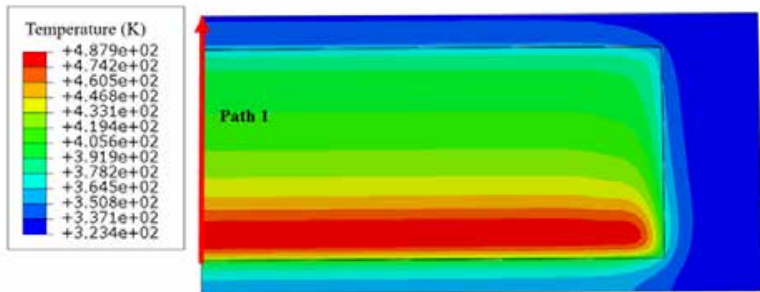

Figure 11: The contour plot of temperature

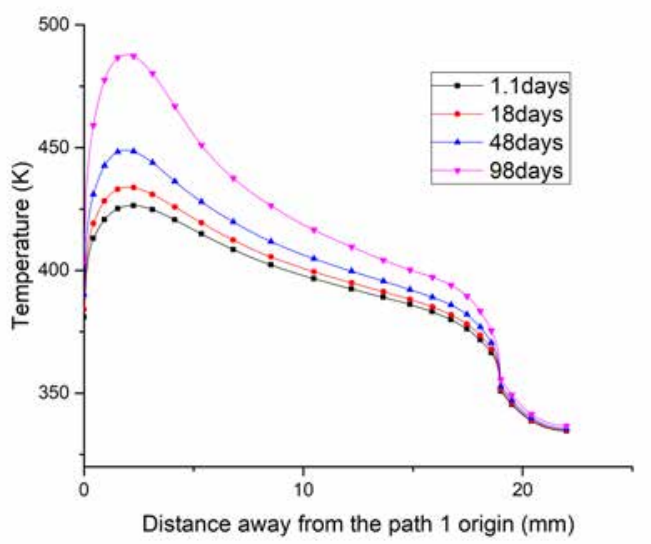

Figure 12: The evolution of temperature along Path 1

\subsubsection{The strain field}

In this study, the deformation contributions of thermal expansion, irradiation creep and irradiation swelling are considered in the fuel meat. Meanwhile, in the cladding the total deformation consists of the thermal expansion and elastic-plastic strains.

As depicted in Fig. 13, the distribution characters of thermal expansion strains in the fuel meat and cladding are similar to that of the temperature. It can also be found that the maximum thermal expansion strain is larger in the cladding than that in the fuel meat, which is due to the greater coefficient of thermal expansion of the cladding. The differences in coefficients of thermal expansion together with the non-homogeneous temperature field and mechanical constraints result in thermal stresses in the fuel plate.

Fig. 14 provides the distributions of equivalent creep strains and swelling strains on the $98^{\text {th }}$ day, and Fig. 15 presents their evolution results along Path 2 (illustrated above in Fig. 10) with variation of the irradiation time. It should be noted the fuel meat in Fig. 2 has been rotated for 180 degrees around the $x$-axis here. 

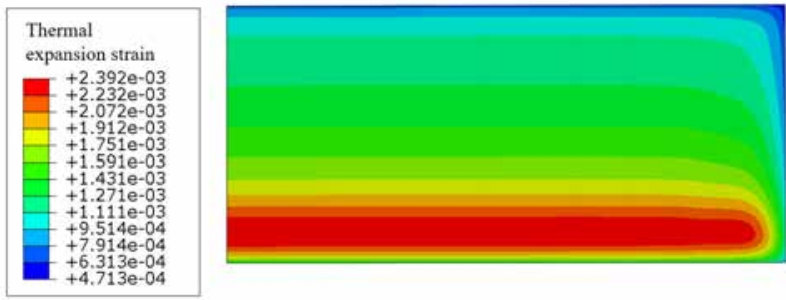

(a)
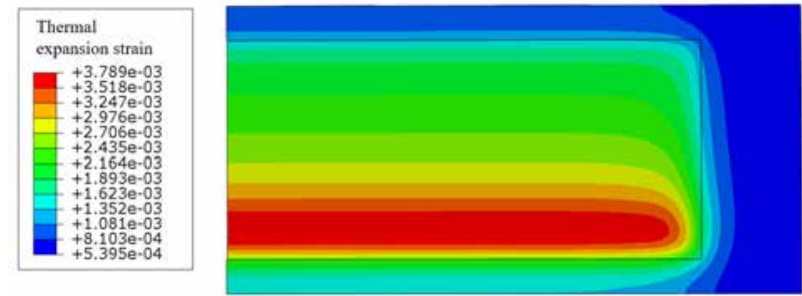

(b)

Figure 13: The contour plots of thermal expansion strains on the $98^{\text {th }}$ day: (a) in the fuel meat; (b) in the cladding

One can see from Fig. 14(a) that the equivalent creep strains are generally higher at the regions at a distance away from the interface between the fuel meat and cladding. The equivalent creep strains are much higher around the heavily irradiated edge, and the maximum equivalent creep strains reach a very large magnitude of $236.4 \%$ at the meat corner. It is known that the equivalent creep strains depend on the Mises stress, the fission rate and the irradiation time, as expressed in Eq. (7). The highest fission rate in the fuel meat appears at locations corresponding to the starting point of Path 2 (depicted in Fig. 14(b)). Hence, it can be obtained that the distribution pattern stems from the Mises stresses in the fuel meat. Fig. 15(a) clearly depicts that (1) the equivalent creep strains increase with irradiation time; in the vicinity of the path origin, the equivalent creep strain decreases first, then increases to a peak value. The distribution character of the equivalent creep strains along Path 2 can be explained by the distribution of the Mises stresses, as given in Section 5.2.3.

As shown in Fig. 14(b), under the heterogeneous irradiation condition, the maximum irradiation swelling strain of $15.79 \%$ exists near the heavily irradiated edge and decreases along the direction of Path 2 as a whole. Owing to consideration of the hydrostatic-pressure dependence of the fission gas swelling, the irradiation swelling strains at the region close to the length ends of the fuel meat are observed to be lower. This can be interpreted since the hydrostatic pressures there must be higher because of in-
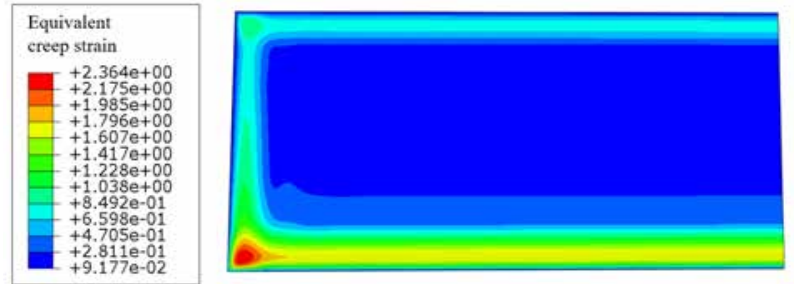

(a)
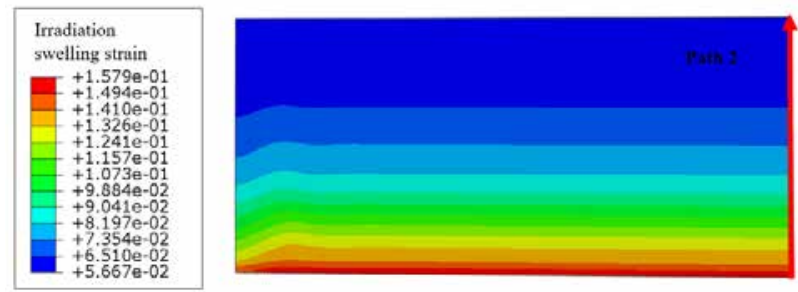

(b)

Figure 14: The contour plots of (a) equivalent creep strains and (b) irradiation swelling strains on the $98^{\text {th }}$ day in the fuel meat

tense mechanical interactions between the fuel meat and the cladding. From Fig. 15(b), it can be clearly seen that the irradiation swelling strains increase with irradiation time; and the swelling strains increase more from the $48^{\text {th }}$ day to $98^{\text {th }}$ day around the path origin than the other regions, which is also related to grain recrystallization occurring earlier there to accelerate the fission gas swelling despite the high irradiation there.

Superposition of the contributions of thermal expansion, irradiation creep and irradiation swelling in the fuel meat results in existence of higher thickness increment at the location with a distance away from the heavily irradiated edge. Thus, a higher temperature can be interpreted there.

Fig. 16 displays the distribution of equivalent plastic strains on the $98^{\text {th }}$ day in the cladding. According to the plastic constitutive theory, the plastic strains are also coupled with the stresses. Besides, the equivalent plastic strains are dependent on the Mises stresses. One can find from Fig. 16 that the equivalent plastic strains are larger in the vicinity of the heavily irradiated region than the interior part, especially at the corner of the meat/cladding interface. This is easy to understand because of the more intense mechanical interaction there. Besides, the thickness of the fuel meat along Path 2 is distributed similarly to equivalent creep strains in Fig. 15(a); thus the locally thickened fuel meat intensifies the extrusion between the fuel meat and the cladding. Path 3 in Fig. 16 goes through the regions having larger equivalent plastic strains. Fig. 17 shows evolution of equivalent plastic strains along Path 3. 


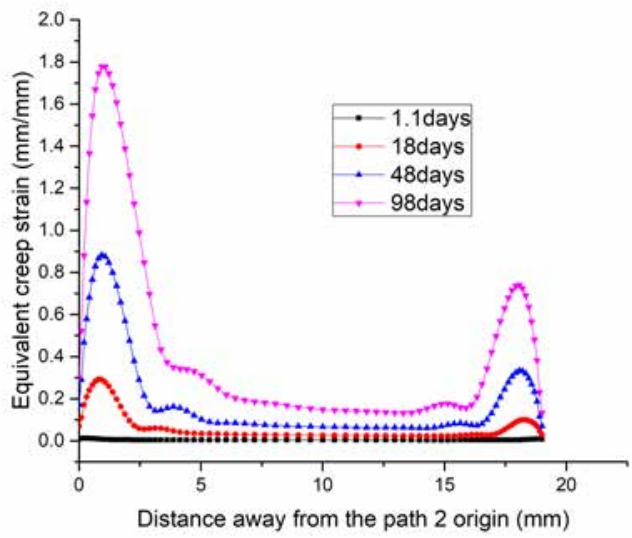

(a)

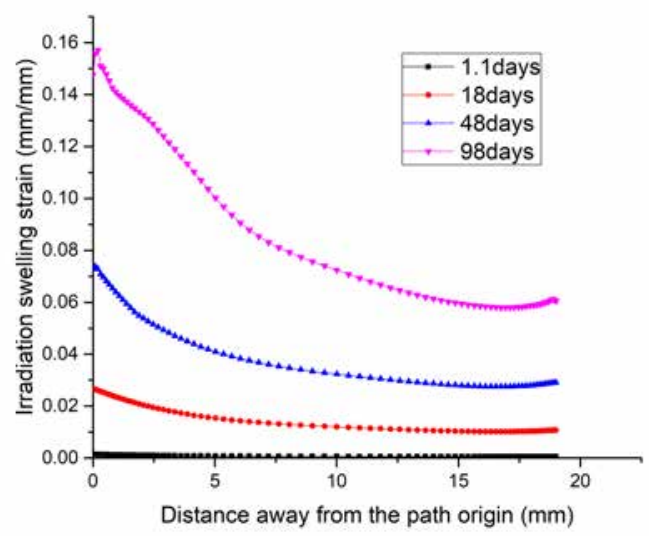

(b)

Figure 15: The evolution of (a) equivalent creep strains and (b) irradiation swelling strains along Path 2
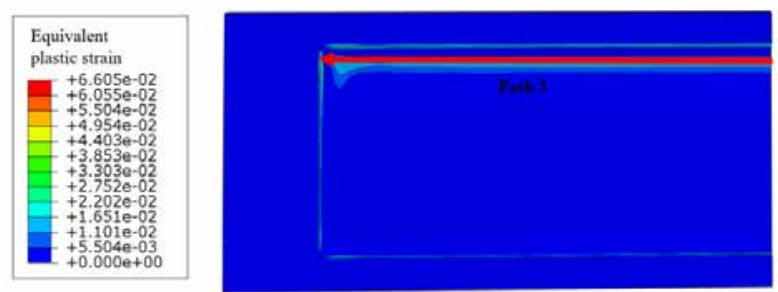

Figure 16: The contour plot of equivalent plastic strains on the $98^{\text {th }}$ day

It is shown that equivalent plastic strains increase with irradiation time; the maximum magnitudes appear near the path end; the distribution and evolution patterns stem from irradiation swelling and creep effects occurring in the fuel meat, as explained above.

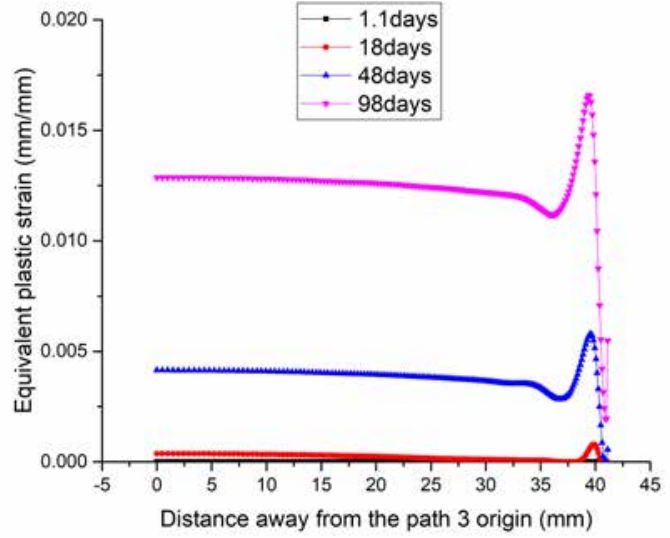

Figure 17: The evolution of equivalent plastic strains along Path 3

\subsubsection{The stress field}

The Mises stresses are coupled with the creep and plastic strains, and they can be used to judge whether the material fails. What's more, the hydrostatic pressure in the fuel meat is considered to be associated with fission gas swelling in this research. So, the Mises stresses and hydrostatic pressure will be discussed in the following.

Fig. 18 provides the distributions of the Mises stresses in the fuel meat and cladding on the $98^{\text {th }}$ day. Fig. 19 presents their evolution histories along path 2 in the fuel meat and Path 3 in the cladding. It should be noted that the contour plot in Fig. 18(a) is obtained by rotating the fuel meat in Fig. 1 for 180 degrees around the $x$-axis.

Comparing the contour plot in Fig. 18(a) with that in Fig. 15(a), we see that the distribution of equivalent creep strains is similar to that of Mises stresses in the fuel meat. Due to the creep relaxation effect, the Mises stress on the $98^{\text {th }}$ day in the fuel meat are quite small, much smaller than that in the cladding. The enlarged irradiation swelling has a trend of giving rise to the Mises stress, while irradiation creep tends to lessen the Mises stress. They both contribute to the evolution of the Mises stresses. As depicted in Fig. 19(a), the highest Mises stress increases quickly from the $1.1^{\text {th }}$ day to the $18^{\text {th }}$ day. One can also observe that there are high stress points at the locations at a distance away from the heavily irradiated edge, which is consistent with the distribution of irradiation creep.

For the Mises stresses in the cladding, one can find from Fig. 18(b) that comparably large Mises stresses mainly emerge in the interface between the fuel meat and the cladding, and the maximum magnitude on the $98^{\text {th }}$ day achieves $403.1 \mathrm{MPa}$. Fig. 19 shows that the Mises stresses increase with irradiation time, and the distribution is con- 

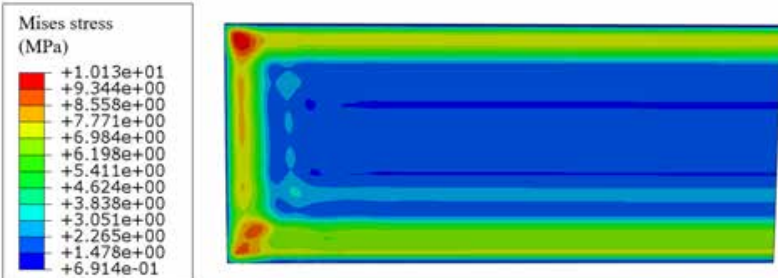

(a)
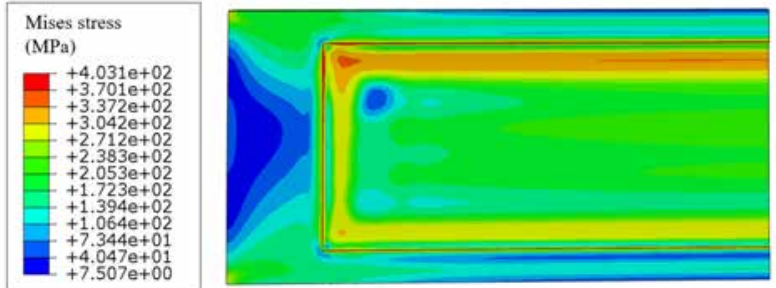

(b)

Figure 18: The contour plots of the Mises stresses (a) in the fuel meat and (b) the cladding

sistent with that of equivalent plastic strain in Fig. 17. Fig. 19(c) shows the Mises stresses normalized by $280 \mathrm{MPa}$, the initial yield stress of A16061, which clearly depicts the strain hardening effect. On the $1.1^{\text {th }}$ day, the normalized Mises stresses are below 1.0, which means the material points have not met the yield condition.

In this study, the hydrostatic pressure differs significantly in the fuel plate, as shown in Fig. 20 which is obtained by rotating the fuel meat in Fig. 2 for 180 degrees around the $x$-axis. The edge effect is remarkable in Fig. 20(a), and the maximum value appears at the meat corner around the heavily irradiated region. This can explain the distribution pattern of swelling strains in Fig. 14(b). The edge effect of hydrostatic pressure is evidently reflected by the results in Fig. 20(b). One can find that the hydrostatic pressures are much higher near the two ends of Path 2 than those in the other locations, which is induced by enhanced mechanical interactions around the edges. With increasing irradiation time, the maximum hydrostatic pressure also rises, which tends to reduce fission gas swelling. The total irradiation swelling strain curve on the $98^{\text {th }}$ day in Fig. 15(b) has lower values in the vicinity of the path origin, which should result from enlarged hydrostatic pressure there.

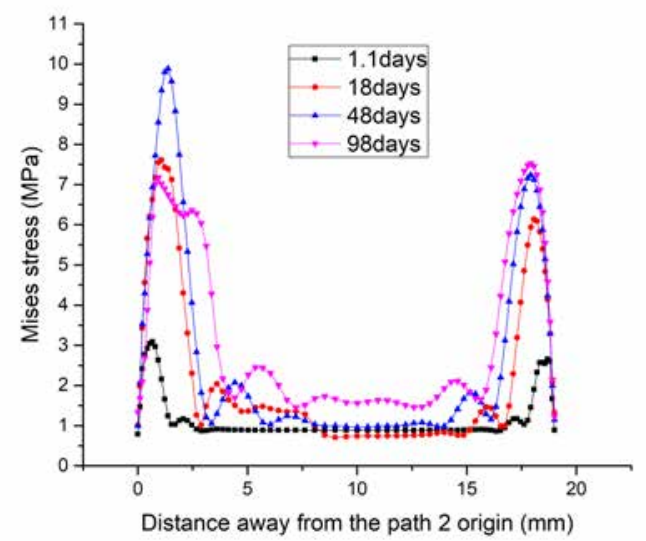

(a)

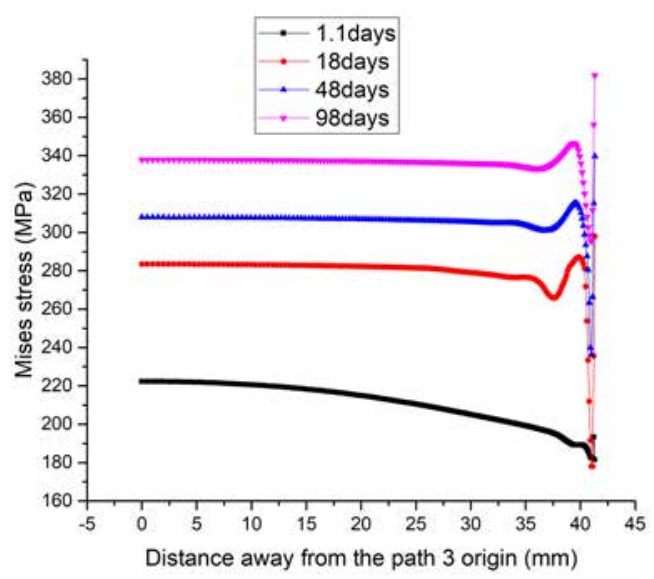

(b)

Figure 19: The evolution of Mises stresses: (a) Mises stresses in path 2; (b) Mises stresses in path 3; (c)Normalized Mises stress in path 3.

\section{Conclusion}

In this study, the three-dimensional stress update algorithm and consistent stiffness modulus for the fuel meat are derived with the irradiation swelling and creep effects involved, where a fission gas swelling model is adopted considering the effects of hydrostatic pressure dependence. The user subroutines UMAT and UMATHT to define the complex thermo-mechanical constitutive relations for the heterogeneous neutron irradiation condition are developed and verified.

Furthermore, the thermo-mechanical behavior of a UMo monolithic fuel plate under an irradiation history of 98 days was simulated and analyzed. The conclusions can be drawn as follows: 

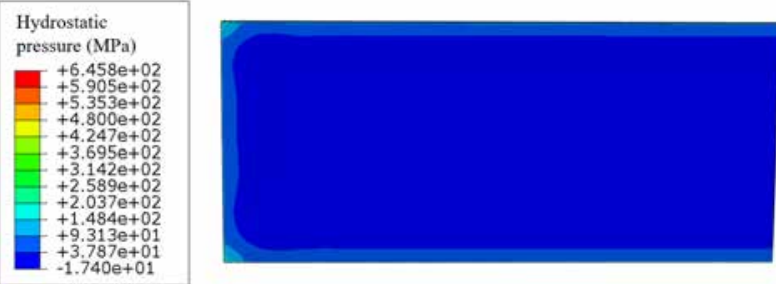

(a)

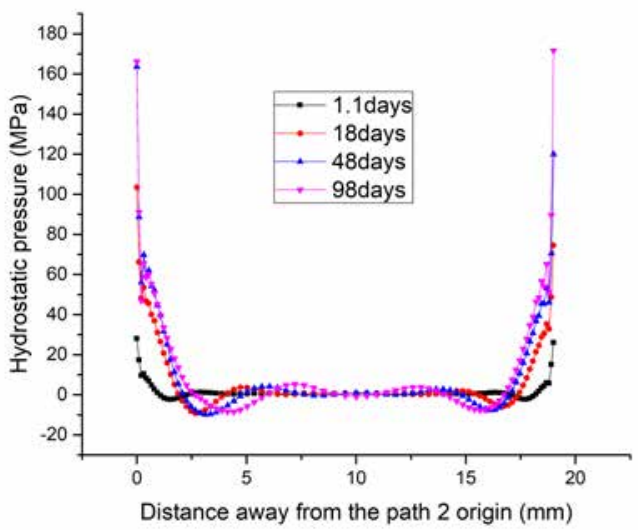

(b)

Figure 20: (a) The contour plot of the hydrostatic pressure on the $98^{\text {th }}$ day in the fuel meat; (b) the evolution history of the hydrostatic pressures along Path 2

(1) The temperature in the fuel meat is much higher than that in the cladding. The distribution characters of thermal expansion strains in the fuel meat and cladding are similar as that of temperature.

(2) With the contributions of thermal expansion, irradiation creep and irradiation swelling, the fuel meat experiences inhomogeneous deformation. The equivalent creep strains are much larger around the heavily irradiated edges. It is found that the irradiation swelling strains at the region close to the throughlength ends of the fuel meat are comparably small due to the high hydrostatic pressures there. The equivalent plastic strains are larger in the heavily irradiated region than the interior part, especially at the corner of the meat/cladding interface.

(3) Large Mises stresses or plastic deformations of the cladding are mainly observed at the interface between the fuel meat and the cladding because of the enhanced mechanical interaction between them.

Acknowledgement: Thanks for the support of National Natural Science Foundation of China (11572091) and the
National Key Research and Development Program of China (2016YFB0700103). S.Y. Hu and D.E. Burkes thank the support from the U.S. Department of Energy, National Nuclear Security Administration, Office of Material Management and Minimization Reactor Conversion Program.

\section{Nomanclature}

$k$ the thermal conductivity $(\mathrm{W} /(\mathrm{K} \cdot \mathrm{m}))$

$\alpha^{T}$ the coefficient of thermal expansion

$T$ the temperature (K)

$T_{0}$ the reference temperature (K)

$\bar{\sigma}$ the equivalent stress (MPa)

$B$ the coefficient of creep rate $\left(\mathrm{m}^{3} / \mathrm{Pa}\right)$

$\dot{f}$ the fission rate (fission $/\left(\mathrm{m}^{3} \mathrm{~s}\right)$ )

$r_{b}$ the radius of intragranular bubble $(\mathrm{m})$

$c_{b}$ the intragranular bubble density $\left(\mathrm{n} / \mathrm{m}^{3}\right)$

$r_{g r}$ the original grain radius (m)

$C_{b}$ the intergranular bubble density $\left(\mathrm{n} / \mathrm{m}^{2}\right)$

the radius of the intergranular bubble $(\mathrm{m})$

$\gamma$ the surface tension $(\mathrm{N} / \mathrm{m})$

$N_{b}$ the gas atom number per intergranular bubble

$N$ the concentration of intergranular fission gas atoms $\left(\mathrm{n} / \mathrm{m}^{2}\right)$

$b_{v}$ Van der Waals constant for Xe ( $\mathrm{m}^{3} /$ atom)

$r_{g r x}$ the grain radius in the recrystallized region (m)

$R_{b x}$ the radius of the intergranular bubble in the recrystal-

lized region $(\mathrm{m})$

$C_{b x}$ the intergranular bubble density in the recrystallized region $\left(\mathrm{n} / \mathrm{m}^{2}\right)$

$p$ the hydrostatic pressure $(\mathrm{Pa})$

$V_{r}$ the volume fraction of the recrystallized region

$q$ the heat generation rate $\left(\mathrm{W} / \mathrm{mm}^{3}\right)$

$\sigma$ the true stress under the axial loading (MPa)

$\varepsilon$ the true strain in the axial loading direction (MPa)

$K_{0}$ the strength coefficient $(\mathrm{MPa})$

$n$ the strain-hardening exponent

\section{References}

[1] 10CFR50, Limiting the use of highly enriched uranium in domestically licensed research and test reactors, Federal Register, 1986, 51: 377.

[2] Meyer M. K., Hofman G. L., Hayes S. L., et al., Low-temperature irradiation behavior of uranium-molybdenum alloy dispersion fuel, J. Nucl. Mater., 2002,304, 221-236.

[3] Mazaudier F., Proye C., Hodaj F., Further insight into mechanisms of solid-state interactions in UMo/Al system, J. Nucl. Mater., 2008, 377, 476-485.

[4] Jo D., Kim H., Safety assessment of U-Mo fuel mini plates irra- 
diated in HANARO reactor, Ann. Nucl. Energy, 2015, 81, 219-226.

[5] Liu R., Prudil A., Zhou W., et al., Multiphysics coupled modeling of light water reactor fuel performance, Prog. Nucl. Energ., 2016, 91, 38-48.

[6] Kim Y. S., Hofman G. L., Fission product induced swelling of UMo alloy fuel, J. Nucl. Mater., 2011, 419, 291-301.

[7] Kim Y. S., Hofman G. L., Cheon J. S., Robsinson A. B., Washs D. M., Fission induced swelling and creep of U-Mo alloy fuel, J. Nucl. Mater., 2013, 437(1-3), 37-46.

[8] Whapman A. R., Electron microscopy observation of the fission gas bubble distribution in $\mathrm{UO}_{2}$, Nucl. Technol., 1966, 2, 123140.

[9] Manley A. J., Transmission electron microscopy of irradiated $\mathrm{UO}_{2}$ fuel pellets, J. Nucl. Mater., 1968, 27, 216-224.

[10] Meyer M. K., Gan J., Jue J. F., et al., Irradiation performance of U-Mo monolithic fuel, Nucl. Eng. Technol., 2014, 46, 169-182.

[11] Rest J., Hofman G. L., An alternative explanation for evidence that xenon depletion, pore formation, and grain subdivision begin at different local burnups, J. Nucl. Mater., 2000, 277, 231238.

[12] Cui Y., Ding S., Chen Z., et al., Modifications and applications of the mechanistic gaseous swelling model for UMo fuel, J. Nucl. Mater., 2015, 457, 157-164.

[13] Miller G. K., Burkes D. E. Wachs D. M., Modeling thermal and stress behavior of the fuel-clad interface in monolithic fuel miniplates, Mater. Des., 2010, 31, 3234-3243.

[14] Miller S. J. and Ozaltun H., Evaluation of U10Mo fuel plate irradiation behavior via numerical and experimental benchmarking, ASME 2012 IMECE, INL/CON-12-25074 PREPRINT.

[15] Zhao Y., Gong X., Ding S., Simulation of the irradiation-induced thermo-mechanical behaviors evolution in monolithic $\mathrm{UMo} / \mathrm{Zr}$ fuel plates under a heterogeneous irradiation condition, Nucl. Eng. Des., 2015, 285, 86-97.
[16] Jeong G. Y., Kim Y. S. Sohn D., Mechanical analysis of UMo/Al dispersion fuel, J. Nucl. Mater., 2015, 466, 509-521.

[17] Ozaltun H., Shen M. H. H., et al., Assessment of residual stresses on U10Mo alloy based monolithic mini-plates during Hot Isostatic Pressing, J. Nucl. Mater., 2011, 419, 76-84.

[18] Booth A. H., Report AECL, Atomic Energy of Canada, 1957.

[19] Spino J., Rest J., Goll W., et al. Matrix swelling rate and cavity volume balance of $\mathrm{UO}_{2}$ fuels at high burn-up, J. Nucl. Mater., 2005, 346, 131-144.

[20] Rest J., A model for the influence of microstructure precipitate pinning and fission gas behavior on irradiation-induced recrystallization of nuclear fuels, J. Nucl. Mater., 2004, 326, 175-184.

[21] Rest J., A model for the effect of the progression of irradiationinduced recrystallization from initiation to completion on swelling of $\mathrm{UO}_{2}$ and U-10Mo nuclear fuels, J. Nucl. Mater., 2005, 346, 226-232.

[22] Gong X., Zhao Y., Ding S., A new method to simulate the microthermo-mechanical behaviors evolution in dispersion nuclear fuel elements, Mech. Mater., 2014, 77, 14-27.

[23] Ko T. H., Ting K., Optimal Reynolds number for the fully developed laminar forced convection in a helical coiled tube, Energy, 2006, 31, 2142-2152.

[24] Najafi H., Najafi B., Hoseinpoori P., Energy and cost optimization of a plate and fin heat exchanger using genetic algorithm. Appl. Therm. Eng, 2011, 31, 1839-1847.

[25] Hajmohammadi M. R., Cylindrical Couette flow and heat transfer properties of nanofluids; single-phase and two-phase analyses. J. Mol. Liq., 2017, 240, 45-55.

[26] Ozaltun H., Shen H., Medvedv P., Numerical Simulation for Mechanical Behavior of U10Mo Monolithic Miniplates for Research and Test Reactors, IMECE, 2011. 